\title{
La cerámica emiral de la campiña de Jaén
}

Juan Carlos Castillo Armenteros*

\section{LA TIPOLOGÍA. CONSIDERACIO- NES PREVIAS}

La construcción de una tipología cerámica es un trabajo que nunca puede ser considerado como un fin en sí mismo, sino que se trataría de un vía con la que obtener fundamentalmente tres objetivos:

I - La sistematización del material.

2 - Establecer la cronología de los contextos arqueológicos, colaborando en su interpretación.

3 - Comparar materiales documentados en otras zonas con el fin de globalizar los análisis.

No obstante, las primeras investigaciones realizadas sobre la cerámica islámica no siguieron estos criterios, sino que en las mismas prevalecieron otros taxonómicos y descriptivos más cercanos a los postulados de la Historia del Arte, inclinando los estudios hacia las denominadas "Cerámicas de Lujo". Como ya indicó H. KIRCHNER (1988), estas clasificaciones se caracterizaban por la prevalencia de los aspectos estéticos y artísticos de las producciones lujosas, principalmente del Verde y Manganeso, Cuerda Seca, etc. (CAMPS, 1943; GONZÁLEZ, 1944; GÓMEZ, 195I; LLUBIA, 1973), sin que interesase la contextualización de las producciones, ni el estudio de las cerámicas "Comunes". En consecuencia, no se intentaba obtener la información histórica y arqueológica que subyace en los conjuntos cerámicos.
Este panorama apenas cambió, a pesar de que empezaron a emplearse otros métodos de clasificación de acuerdo con los aspectos funcionales de los recipientes (LLUBIA, 1973), sobre todo porque en estas clasificaciones se desechaba gran cantidad de material fragmentado, por otra parte el más abundante, pero que no interesaba por su escaso valor estético, y por su supuesta escasa contribución a la elaboración de una tipología formal. De esta manera, las tipologías se circunscribían al estudio de piezas más o menos completas.

En la actualidad, y a pesar de que la abundante cantidad de seriaciones efectuadas a partir de excavaciones y secuencias estratigráficas, la mayor parte de los estudios siguen teniendo como objetivo principal los aspectos tipológicos y descriptivos, que aportan cronologías demasiado imprecisas, lo que ha impedido correlacionar formas, cronologías y áreas geográficas, y producir un aumento cualitativo de los conocimientos sobre este tema.

La mayoría de las clasificaciones han sido efectuadas en función de los criterios tipológicos básicos propuestos por G. Roselló (1978; 1983), e incluso la mayor parte de las investigaciones que han optado por otra vía distinta, han mantenido líneas de conexión con dicho sistema, de forma que en ocasiones puede dar la impresión de que existe una sola forma de establecer la tipología, lo que desde luego es erróneo. Una de las principales causas que ha

\footnotetext{
* Universidad de Jaén, Área de Historia Medieval. Grupo de Investigación del Patrimonio Arqueológico de Jaén
} 
contribuido a frenar la multiplicación de métodos, ha sido el escaso grado de precisión cronológica que se ha alcanzado, de tal manera que se ha impedido un aumento de la complejidad de las tipologías.

\section{LAS CERÁMICAS EMIRALES EN LA CAMPIÑA DE JAÉN. LA METODO- LOGÍA DE LA CLASIFICACIÓN}

Nuestra propuesta tipológica, expuesta por primera vez en la reunión de Arqueología y Patrimonio de Salobreña celebrada en 1990 (SALVATIERRA Y CASTILLO, 1993a), parte de las tipologías establecidas, desarrollando nuevas vías de trabajo, que nos permitan:

A - Analizar una mayor cantidad de fragmentos cerámicos procedentes del registro arqueológico, tanto de la prospección como de la excavación, que de otra manera hubiesen sido desechados.

B - Reducir el grado de subjetividad que conlleva el estudio meramente formal.

C - Establecer mayores precisiones cronológicas con el objetivo de lograr en un futuro, aún lejano, la determinación de pervivencias culturales, detectar tradiciones locales, y si es posible, relacionar materiales y grupos étnicos.

Por ello, proponemos el análisis sistemático del material mediante criterios morfométricos aplicados a las bases y bordes de los recipientes (RíSQUEZ et alii, 1991; RíSQUEZ, 1993; MOLINOS et alii, 1995; RíSQUEZ, 1995), estableciendo después las variantes a través de los Análisis Multivariante (CASTILLO, 1995).

No obstante, aunque este tipo de análisis es capaz de generar Tipos, Subtipos y Variantes, proponemos un método de trabajo diferente. En primer lugar, y como punto de partida, elaboramos una Tipología Formal realizada en función de los aspectos tecnológicos, formales, funcionales, tipológicos y decorativos de los recipientes cerámicos. Esta clasificación subjetiva está estrechamente relacionada con las empleadas por los demás arqueólogos medievalistas. De la misma obtenemos varias series que están suficientemente contrastadas y que facilitarán la comparación de los resultados con los obtenidos por otros modelos. En segundo lugar, para la determinación de los Tipos que configuran cada serie se ha optado por un criterio morfométrico, definido por diversas variables obtenidas en los bordes y bases de los recipientes, que indican verticalidad, horizontalidad, exvasamiento, grosores y tamaño, generando una Tipología Estadística (CASTILLO, 1995).

En este articulo haremos referencia tan solo a la Tipología Formal, dejando para un futuro trabajo de mayor extensión el resto de la propuesta metodológica.

\section{LA TIPOLOGÍA FORMAL}

Una característica común a las zonas para la que se han establecido tipologías emirales consistentes, y nuestra propia área de trabajo, es la presencia de materiales elaborados a torneta/mano, junto a otros fabricados a torno alto, rasgo que hemos considerado prioritarios. A partir de aquí hemos estructurado los diferentes grupos en función de los caracteres formales (Formas Abiertas y Cerradas), y a continuación clasificando los recipientes según la función para la que fueron realizados, situando en un cuarto nivel los tipos básicos establecidos por G. Roselló (1978; 1983), pero aceptando algunas de las "integraciones" propuestas por Acién y su grupo (ACIÉN et alii, En prensa), por considerarlas especialmente operativas, para terminar con el análisis del acabado final de la pieza (Tabla I).

El estudio se ha realizado con 1.264 fragmentos, divididos en varios bloques: Bordes, Bases, Asas, Cuellos y Cuerpos. Naturalmente también se han tenido en cuenta otros elementos susceptibles de identificar perfectamente una pieza, como la piquera o la cazoleta de candil, la rejilla de la Jarra-colador o la pesa de telar, no obstante estos son porcentualmente casi inapreciables. Sí hemos incluido las "patas" pertenecientes a las Ollas trípodes por ser un elemento característico del 
período emiral del Alto Guadalquivir y porque su incidencia en el conjunto cerámico es muy importante.

Así mismo, resaltar, que los porcentajes de materiales más representativos son los aportados por los asentamientos de Cerro Miguelico (SALVATIERRA Y AGUIRRE, 1987a y b) y Cerro del Castillo de Peñaflor (SAlvatierRA, AGUIRRE Y CASTILLO, 199I; SALVATIERRA Y CASTILLO, 1992, 1993b, 1995) (SALVATIERRA, CASTILLO Y PÉREZ, 1992) que son aquellos donde se han efectuado excavaciones arqueológicas por haberse detectado niveles emirales. El resto del material procede de excavaciones sistemáticas, prospecciones con sondeo estratigráfico, urgencias y excavaciones de apoyo a la restauración de muy distintas épocas y que por ello aportan cantidades de material bastante inferiores. Junto a ello se han incorporado los elementos cerámicos recogidos en las diversas prospecciones que aportan individualmente un número de fragmentos aún más reducido, pero pese a ello de gran interés para el estudio de la distribución del poblamiento de la Campiña de Jaén (Fig. I).

Para el desarrollo de nuestro estudio formal, la muestra quedará dividida en dos grandes bloques, establecidos en base a sus atributos tecnológicos, subdivididos a su vez en compartimentaciones más pequeñas, en función de los aspectos formales:

\section{A.- RECIPIENTES ELABORADOS A TORNETA/MANO.}

Constituye un amplio grupo, en él se incluyen todos aquellos recipientes elaborados con torno lento/torneta o bien realizados a mano, es decir aquellos realizados principalmente en base a dos procesos de elaboración:

- El Modelado Manual, efectuado a través del sistema denominado de urdido, consistente en colocar sobre una plancha de arcilla, rollos de barro que configuran y levantan las paredes del recipiente, en este proceso de fabricación no interviene ningún instrumento (MATESANZ, 1987).
- El Torno Lento/Torneta, utilizada por el alfarero para facilitar la fabricación del recipiente. En esta técnica se funde el urdido y la fuerza centrífuga que proporciona el instrumento mecánico (GUTIÉRREZ, 1988). Este instrumento consiste en una rueda apoyada en un eje de rotación, y este, a su vez, sobre una base estable, aunque puede acoplar otros elementos con el objetivo de facilitar el sistema de equilibrio, como una placa de madera o una segunda rueda unida a la rueda con tensores (CORTES, 1954; 1958; FEITO, 1985).

Esta técnica de fabricación que combina el urdido con la fuerza centrífuga de la torneta, genera dos tipos de torneados (MATESANZ, 1987). En el Torneado Intermitente, el alfarero modela la pieza con las dos manos aprovechando la fuerza de rotación de la rueda, que es impulsada intermitentemente con la mano por el propio alfarero. $Y$ en segundo lugar, el Modelado, en este se modela la pieza con el sistema de urdido, utilizándose la torneta para facilitar y perfeccionar el modelado manual.

Este proceso ha dejado múltiples huellas físicas en el recipiente que permiten identificar esta técnica (GUTIÉRREZ, 1988; GÓMEZ, 1992).

A pesar de estas significativas marcas que diferencian las cerámicas elaboradas a torneta de las modeladas a mano y torno, a la hora de diferenciarlas nos hemos encontrado con diversas dificultades, sobre todo, porque si ya resulta complicado determinar el proceso seguido al examinar las huellas dejadas por el alfarero, generalmente encubiertas por alisados y otros procesos de acabado del recipiente, la dificultad aumenta, al contar con una muestra muy erosionada y fragmentada que impide determinar con exactitud la técnica utilizada.

Ante esta problemática, y con el fin de tratar de obtener resultados clarificadores, hemos iniciado una serie de estudios en la línea de los trabajos emprendidos por la Dra. Rísquez en el Área de Prehistoria y Arqueología del Departamento de Territorio y Patrimonio Histórico de la Universidad de Jaén. Se trata básicamente de la utilización de radiografías efectuadas a los fragmentos cerámicos con las 
que es posible observar con más claridad la técnica utilizada para su elaboración, a través de la determinación de las huellas internas presentes en los fragmentos cerámicos y que son significativas de la utilización de una u otra técnica alfarera, como la distribución de las vacuolas, distribución y orientación de los minerales que componen el desgrasante, líneas de torno, etc, indicios que sólo se aprecian con un estudio radiográfico de la pieza. Hasta el momento, y teniendo en cuenta que las investigaciones acaban de comenzar, sólo se han obtenido resultados significativos a la hora de distinguir los recipientes elaborados a torno de los fabricados a mano o a torneta, estando aún en proceso de estudio las características que permiten diferenciar estos dos últimos grupos, ya que los análisis efectuados con fragmentos elaborados con la torneta indican que las huellas de los mismos son muy similares a las documentadas en los recipientes elaborados a mano. Esta semejanza interna deriva posiblemente de la gran similitud en la fabricación, ya advertida por Matesanz (1987) cuando señalaba que en realidad la torneta es sólo un instrumento auxiliar de la fabricación a mano, o bien pueden alcanzarse resultados parecidos a los del torno, porque la velocidad de rotación que se le puede imprimir es similar a la de aquel. Hemos de reconocer que si no fuese posible avanzar en el análisis radiográfico, el mismo no pasaría de ser una curiosidad, sin auténtica utilidad. No obstante, el continuo avance de las técnicas radiográficas permite esperar resultados.

Ante los inconvenientes para la distinción física entre materiales elaborados a mano o torneta, hemos preferido agruparlos para su estudio tipológico.

Dentro del mismo distinguimos dos bloques diferenciados por la forma del recipiente, Abiertos y Cerrados:

\section{A.I. ABIERTOS:}

Aquellos que poseen un diámetro de la boca superior, igual o muy poco inferior al diámetro de la panza (BAZZANA, 1979). La única serie que configura este grupo está definida por un recipiente de Cocina, la CAZUELA. Está elaborada con pastas de tonalidades rojizas o marrones con desgrasante grueso. Los elementos que conservan sus bases nos indican que son planas o ligeramente convexas (Fig. 2; No I, 3 y 5). De los fragmentos conservados tan sólo uno presenta un asa, que arranca desde la base y llega hasta el borde del recipiente, se trata de un evidente asidero de grandes proporciones y de sección lenticular (Fig. 2; $\mathrm{N}^{\circ} \mathrm{I}$ ).

A juzgar por la forma del borde o por la del cuerpo del recipiente distinguimos dos tipos:

Tipo I - Cazuela de borde plano, con paredes, rectas muy verticales o con exvasamiento externo (Fig. 2; $N^{0} \mid$ y 2). Posee paralelos en Granada (GÓMEZ, 1992, n² 20, n² 25). No se recoge en la tipología general del S.E. de al-Andalus (ACIÉN et alii, En prensa).

Tipo II - Cazuela de borde redondeado, con paredes rectas o con distinto grado de curvatura (Fig. 2; No 3 y 4). Existen paralelos de este tipo de cazuela en Bayyana (CASTILLO Y MARTínEZ, 1993, pág. 83, lám. III-I), Málaga (ACIÉN, 1986, pág. 254, fig. 4-4), Málaga y Almería (ACIÉN Y MARTíNEZ, 1989, pág. 126, fig. 1-1), Granada (MOTOS, 1991, pág. 35, fig.3-1; 1993, pág. 21 I, fig.। - I5; GÓMEZ, 1992, n०22, n 28; 1993, pág. 181, fig. 1-8). Y presenta las mismas características que el tipo de cazuela elaborado a torneta de la clasificación general establecida para la zona del S.E. de al-Andalus (ACIÉN et alii, En prensa, n 5 II).

\section{A.2. CERRADOS:}

Son aquellos recipientes que presentan un diámetro en la panza superior al de la boca (BAZZANA, 1979). Este grupo está formado por dos tipos de recipientes:

\section{A.2.I. Cocina:}

- OLLA / MARMITA. La olla o marmita elaborada a mano/torneta, a grandes rasgos, son recipientes modelados con pastas rojas o marrones, similares a las de las cazuelas, con abundante desgrasante mineral (cuarzos, piritas, etc.). Tiene cuerpo globular, y presentan 
dos asas de puente de sección lenticular, que arrancan de la parte superior del cuerpo hasta enlazar con el borde. Sus bases son planas o convexas (Fig. 3), destacando principalmente estas últimas en aquellos recipientes que llevan acoplados tres vástagos o patas que suelen ser de unos $10 \mathrm{~cm}$. de longitud, configurando lo que se ha definido como olla trípode (Fig.3; No I, 2 y 3) (SALVATIERRA Y CASTILLO, 1993a). Esta característica también suele aparecer, aunque en menor número de ejemplares, en ollas con base plana. Este tipo de olla, también documentado en el grupo de las elaboradas a torno, no ha sido localizado en otras zonas de al-Andalus, constituyendo un particularismo propio de la región del Alto Guadalquivir durante el período emiral.

La existencia de pocas vasijas que conserven su perfil completo nos impide realizar un estudio pormenorizado de la forma del cuerpo, y por tanto hacer una clasificación en base a las características de este.

Con respecto a los bordes, las diferentes formas documentadas nos permiten definir varios tipos de ollas:

Tipo I - Olla de borde redondeado, está caracterizada por un cuerpo globular, pudiendo tener un cuello de reducidas dimensiones o prescindir del mismo (Fig. 2; $\mathrm{N}^{\circ}$ 10-22). Tiene paralelos en Granada (MOTOS, 1986, pág. 40I, fig. 3-I; I99 I, fig. 4); Málaga (ACIÉN, 1986, pág. 253, fig. 3-I), Almería (CASTILLO Y MARTínEZ, 1993, pág. 79, fig. 1-7). Huelva (FERNÁNDEZ, 1989, pág. 206, fig. 1, 8), Madrid (CABALLERO, 1989, fig. 9, fig. 10) y en Levante (GUTIÉRREZ, 1988, ARI9).

Tipo II - Olla de borde bífido, tiene cuerpo globular y un pequeño cuello (Fig. 3; No 4 y 5). Tipos similares se han localizado en el yacimiento de Montefrío (MOTOS, 1991, fig. 5) y Bayyana (CASTILLO Y MARTíNEZ, 1993, pág. 8I, lám. II-I), aunque efectuadas a torno.

Tipo III - Olla de borde recto, constituye un grupo muy frecuente junto a la del tipo I, se caracteriza por un cuerpo globular y un cuello corto, o sin éste, lo que puede originar un exvasamiento externo del borde. (Fig. 3;
NN 6-13) Tipos similares se localizan en gran número de asentamientos del Sureste peninsular (MALPICA, 1993), así como en Cuenca (ALVAREZ, 1989, pág. 111, fig.l-5,10), Alicante (GUTIÉRREZ, 1988, ALI5, F7,F8) y Huelva (FERNÁNDEZ, 1989, pág. 206, fig. I-5).

Tipo IV - Olla de borde triangular, principalmente, como las anteriores, tienen cuerpo globular, aunque carecen de cuello, determinando un borde sin apenas exvasamiento externo (Fig. 3; $\mathrm{N}^{\circ}|4-| 8$ ). Existen formas semejantes en asentamientos del área Alicantina (GUTIÉRREZ, 1993, pág. 50, fig. 5-9; 1988, ALI 4,AL23,G35,G36); AZUAR, 1989, pág. 103, n 158), y Huelva (FERNÁNDEZ, 1989, pág. 206, fig. 1-1,2). También se encuentra clasificada como uno de los tipos de olla a torneta en la tabla tipológica del S.E de al-Andalus (ACIÉN et alii, En prensa, 4I2).

Tipo V - Olla de borde apuntado, son muy escasos los elementos que presentan este tipo de borde, no poseen cuello y tienen cuerpo globular (Fig. 4, No I-5). Tipos muy semejantes se han localizado en Bezmiliana (ACIÉN, 1986, pág. 252, fig. 2-2), el Maraute (GÓMEZ, 1992, n 16), Málaga (IÑIGUEZ Y MAYORGA, 1993, pág. 134, fig. 9-5) y Marmuyas (NAVARRO, 1991, pág. 56, fig. 8 -NO-I-121). Algunos de los recipientes clasificados dentro de este tipo guardan cierta similitud con el tipo 4I I de la clasificación realizada para el S.E. de al-Andalus (ACIÉN et alii, En prensa).

Tipo VI - Olla de borde con engrosamiento interno, son sólo cuatro fragmentos los localizados, poseen cuerpo troncocónico invertido con borde reentrante (Fig. 4; $N^{\circ} 6$, 7 y 8). Existe una forma parecida pero efectuada a torno en Bayyana (CASTILLO Y MARTÍNEZ, 1993, pág. 8I, lám. ||-|I).

\section{A.2.2 . Mesa:}

- JARRO - Son recipientes elaborados con pastas rojas o grises, que incorporan un desgrasante grueso, se definen como recipientes de base plana y cuerpo globular, de cuello cóncavo y borde trilobulado, poseen un asa de puente de sección plana o lenticular de grandes proporciones, no suelen ir decorados. Por la forma de su labio, podemos distinguir dos tipos: 
Tipo I - Jarro de labio redondeado o apuntado (Fig. 4; No 9, 10 y II), posee paralelos en el Maraute (GÓMEZ, 1992, n 62) y en Alicante (GUTIÉRREZ, 1988, Z8,Z9)

Tipo II - Jarro con doble engrosamiento (Fig. 4 ; No 12 y 13 )

Estos tipos de Jarros elaborados a mano/torneta están ausentes de la tipología general establecida para el S.E de al-Andalus (ACIÉN et alii, En prensa).

\section{A.2.3. Contención:}

- TINAJA - Son recipientes de base plana y cuerpo ovoide, están elaboradas por partes, que posteriormente se van uniendo, cubriendo la línea de unión con una cinta o cordón en relieve, que alberga decoración impresa o incisa, el material empleado para su fabricación son arcillas de tonalidades rojas o marrones y amarillas, que incorporan desgrasantes gruesos. La forma del borde nos permite distinguir tres tipos:

Tipo I - Borde Redondeado, presenta engrosamiento tanto interno como externo (Fig. 4; No 14 y I5), con o sin cuello. Existen paralelos de este tipo de tinaja en el Castillón (MOTOS, 1991, fig. 13-25,26) y Bayyana (CASTILLO Y MARTÍNEZ, 1993, pág. 96, lám. XI-I)

Tipo II - Borde Recto, no presenta engrosamientos, carece de cuello (Fig. 4; No 16 y 17).

Tipo III - Borde Moldurado, posee cuello, que puede ser cóncavo, convexo o recto. La molduración subdivide este tipo en tres variantes:

Variante III.I - Labio Triangular, presenta un engrosamiento externo que determina un perfil triangular (Fig. 4; No 18 y 19). Este tipo es muy común en los asentamientos de todo el Sureste de al-Andalus (MALPICA, 1993, pág. 46, fig. 3-8; pág. 96, lám. XI-2, pág. I|4, lám. XXI-1,2, pág. |87, fig. 315, pág. 224, fig.9-1,9,10, 15).

Variante III.2 - Labio Cuadrado, posee un engrosamiento externo que define un perfil cuadrado (Fig. 4; $\mathrm{N}^{\circ} 20$ ), incorpora una canaladura exterior. Se asemeja bastante al tipo 2.7.2.a del Castillón (MOTOS, 1991, fig. 13-13) y el Maraute (GÓMEZ, 1992, n69,70) y Bayyana (CASTILLO Y MARTÍNEZ, 1993, pág. I I4, lám. XXI-9).

Variante III.3 - Labio Engrosado, posee un cuello convexo y doble engrosamiento, que define un borde reentrante (Fig. 4; $\mathrm{N}^{\circ} 2 \mathrm{I}$ ).

\section{A.3. OTRAS FORMAS:}

Dentro de este grupo definimos un recipiente de Cocina muy común para la mayor parte de los asentamientos, constituyendo otro elemento característico de los mismos, la TAPADERA/DISCO. Poseen grandes dimensiones y forma circular, están modeladas con pastas rojas o marrones que incorporan desgrasantes gruesos de micas y cuarzos. Según la forma del borde podemos distinguir dos tipos básicos:

Tipo I - Tapadera de borde no diferenciado, presenta una base plana o ligeramente cóncava o convexa, la forma del mismo puede ser redondeada, recto o bien apuntada (Fig. 5; $\mathrm{N}^{\circ} \mid$ - 4). En los fragmentos documentados no hay indicios, ni marcas de asideros. Este tipo de tapadera/disco suele aparecer en todo el sur-este de al-Andalus (MALPICA, 1993, pág.47, fig. 4-2,3,4,5,6; pág.83, lám. III-7,8; pág. 225, fig. 10-I al 13 ). Alicante (GUTIÉRREZ, 1988, AL25, AL26, AL27) y Marmuyas (NAVARRO, 1991, fig. 14).

Tipo II - Tapadera con reborde, poseen base plana aunque irregular, su borde presenta una sección que oscila desde un simple engrosamiento a una pequeña cresta que reproduce un perfil diverso, redondeado, cuadrangular, apuntado (Fig. 5; No 5 - 10). Algunas de ellas muestran indicios de un asa de puente con sección lenticular. Tipos similares se han localizado en Granada (GÓMEZ, 1992, n 39,45, 46), Almería (CASTILLO Y MARTíNEZ, 1993, pág. 102, lám. XIII11,12), Málaga (ACIÉN, 1986, pág. 262, fig. 12), Marmuyas (NAVARRO, 1991, fig. 15), Córdoba (FUERTES et alii, 1993, Lám. 3), Murcia (NAVARRO, 1986, pág. 163, n 352) y Alicante (GUTIÉRREZ, 1988, G66,Z7).

Ambos tipos de tapaderas son muy comunes en los yacimientos andaluces del S.E. de 
al-Andalus, como indica la tipología general elaborada para esta zona de España (ACIÉN et alii, En prensa).

\section{B. RECIPIENTES ELABORADOS A TORNO RÁPIDO}

Tecnológicamente estos elementos han sido modelados en base a la fuerza giratoria que produce un torno alto, compuesto principalmente por dos ruedas, unidas entre sí con un eje giratorio. En la rueda superior se elabora el recipiente, mientras que la inferior se utiliza para efectuar el movimiento del torno impulsándolo con el pie.

Este grupo de recipientes se estructura de la misma forma que dividimos las cerámicas elaboradas a mano/torneta, es decir en recipientes abiertos y cerrados.

\section{B.I. ABIERTOS:}

Está formado por tres tipos de recipientes según el uso o función para la que fueron creados:

\section{B.I.I. Cocina:}

- CAZUELA - Están realizadas con pastas rojas o marrones que incorpora un desgrasante fino, aunque no conservamos sus bases, estas serían planas. Entre los cuatro fragmentos documentados, distinguimos dos tipos claramente definidos:

Tipo I - Cazuela de cuerpo troncocónico invertido, su principal característica reside en el exvasamiento externo que le imprime su cuerpo troncocónico invertido, poseería base plana, constituyendo un tipo muy similar al documentado en Huelva (FERNÁNDEZ, 1989, pág. 208, fig. 2-25) y en el S. E. de al-Andalus (ACIÉN et alii, En prensa, $n^{\circ} 512$ ). Su labio está engrosado exteriormente, definiendo un borde triangular, que en algunos casos puede ser bífido (Fig. 2; $N^{\circ} 6$ y 7 ).

Tipo II - Cazuela de paredes carenadas, como el anterior también tendría base plana, presentan una marcada carena en la parte central del cuerpo. Podemos distinguir dos variantes dentro de este tipo:

Variante II.I - Cazuela con borde de tendencia exvasada, aquellas que poseen en el extremo superior del cuerpo y el labio una clara tendencia hacia el exvasamiento externo (Fig. 2; No 8). Cazuelas con carenas pronunciadas se han clasificado en la tipología establecida para el S.E. de al-Andalus (ACIÉN et alii, En prensa, 5/3). Pueden presentar un labio apuntado o redondeado.

Variante II.2 - Cazuela con borde de tendencia reentrante, aquella en las que el extremo superior del cuerpo y su borde muestran una inclinación hacia el interior del recipiente (Fig. 2; $N^{\circ}$ 9), posee un borde redondeado con leves engrosamientos externo e interno.

\section{B.I.2. Mesa:}

Tan sólo lo compone una serie tipológica:

ATAIFOR/CUENCO. Una característica común para toda nuestras piezas, es su elaboración a torno, no existiendo ningún ejemplar realizado a mano/torneta, como ocurre en otras zonas (GUTIÉRREZ, 1988; GÓMEZ, 1992). Están realizados con pastas claras, blanca o amarilla, y rojas, muy decantadas. Sus bases son planas 0 con repie anular de reducidas dimensiones (Fig. 5; No 21 / Fig. 6; $N^{\circ} \mid$ y 2). Algunos de ellos están vidriados tanto en su pared interna como externa, el color predominante es el verde para ambas caras, y en algunos casos se aprecian manchas de manganeso, existiendo un ejemplar en marrón y otro en melado. Tan sólo un elemento presenta motivos decorativos realizados en verde-manganeso. Por la forma de su labio podemos distinguir varios tipos:

Tipo I - Ataifor de labio Apuntado o Redondeado, se caracteriza presentar un perfil redondeado, unas veces sin engrosamientos, mientras que otras presentan engrosamientos internos, o bien externos (Fig. 5; No 10 - I8), con una línea incisa que marca el labio. Sus paredes son inclinadas y curvas, aunque pueden en algunos casos presentar una carena en 
el centro del cuerpo. Existen paralelos en Almería (CASTILLO Y MARTíNEZ, 1993, pág. 84, lám. IV4,6), Granada (MOTOS, 1991, pág.33, fig. 1-3,4; GÓMEZ, 1992, n' 93, 94, 95, 96). Con respecto a los elementos vidriados formas similares se han localizado en el Maraute (Granada)(GÓMEZ, 1992, № I50, 160), Málaga y Almería (ACIÉN Y MARTÍNEZ, 1989, pág. 127, fig. 2-8,9), Bayyana (CASTILLO Y MARTíNEZ, 1993, pág. 84, lám. IV-7; pág. 106, lám. XVI-2,4,5,6), Córdoba (FUERTES et alii, 1993, lám. 2). Finalmente está incluido como un tipo de ataifor emiral en la tipología general del S.E. de al-Andalus (ACIÉN et alii, En prensa, I I2)

Tipo II - Ataifor de labio con engrosamiento externo (Fig. 5; No 19 y 20), poseen paredes rectas muy exvasadas. Recipientes similares se han documentado en Marmuyas (NAVARRO, 1991, pág. 50, fig. 2) y El Maraute (GÓMEZ, 1992, $\left.N^{\circ} 152,153,155\right)$ y en el nivel II de Bayyana (CASTILLO Y MARTíNEZ, 1993, pág. 106, lám. XVI-7,8,9).

Tipo III - Ataifor de labio Vuelto, se caracteriza por presentar una base plana y unas paredes rectas muy inclinadas. El labio esta vuelto a modo de ala, de pequeñas dimensiones, decorada con trazos en color rojo (Fig. 5; $\mathrm{N}^{\circ} 2 \mathrm{I}$ ). Se han documentado algunos tipos similares en Bayyana (CASTILLO Y MARTíNEZ, 1993, pág. 85, lám. $v$ ), aunque con mayores dimensiones y paredes más curvas, y por lo general vidriados.

Estos tipos presentan las características propias de los ataifores incluidos en la tipología general del S.E. de al-Andalus (ACIÉN et alii, En prensa, III, I I y | | 3) aunque vidriados.

\section{B.I.3. Uso Múltiple:}

ALCADAFE/LEBRILLO: Como los ataifores, son muy escasos los recipientes que con esta denominación que están realizados a mano/torneta en Andalucía, tan sólo se han encontrado un elemento en la costa granadina (GÓMEZ, 1992, № 48, 49), sin embargo sí son más comunes en el área levantina (GUTIÉRREZ, 1988, pág. 79, G52, G53, G55), en ambos casos este tipo de recipiente posee características similares.

Las vasijas recuperadas en la Campiña del Guadalquivir están realizados en pastas claras y rojas con desgrasantes de diversos tamaños. Sus bases son planas (Fig. 6; No 17 y I8), las diferencias existentes en sus cuerpos determinan dos tipos de recipientes:

Tipo I - Alcadafe de Cuerpo Cilíndrico, se caracteriza por la verticalidad de las paredes de su cuerpo, posee sin lugar a dudas base plana y están realizados en pastas rojas o marrones con desgrasante grueso. Atendiendo a la forma que adoptan sus bordes podemos determinar dos Subtipos o variantes:

Variante I.I - Alcadafe con labio plano o redondeado y leve engrosamiento externo (Fig. 6; $\mathrm{N}^{\circ} 3$ y 4). Se ha documentado una forma similar en Marmuyas (NAVARRO, 1991, fig. 9 EO4-8-2).

Variante 1.2 - Alcadafe de labio plano con ala (Fig. 6; No 5 y 6), el único paralelo que posee caracteres similares se localizó en Bezmiliana (ACIÉN Y MARTíNEZ, 1989, pág. I33, fig. 6-5), aunque con el cuerpo trococónico invertido.

Este primer tipo de alcadafe en sus dos variantes posee escasos paralelos en otras zonas donde se han efectuado análisis tipológicos, por lo que podemos identificarlo como un elemento particular de la Campiña Giennense.

Tipo II - Alcadafe de Cuerpo Troncocónico Invertido, se caracteriza por la inclinación de sus paredes, mostrando un significativo exvasamiento externo. Están elaborados principalmente con pastas claras, amarilla y naranja, con desgrasante mediano. Los matices y formas presentes en sus bordes establecen dos variantes:

Variante II.I - Alcadafe de labio con amplio engrosamiento externo, constituye un tipo muy común en numerosos asentamientos de esta época de Almería, Granada, Málaga (MALPICA, 1993, pág. 95, lám. X-8; pág. I 12, lám. XX-1,4; NAVARRO, 1991, fig. 9-FOI-17), en Huelva (FERNÁNDEZ, 1989. pág. 210, fig. 3 - 17, 18, 19, 20, 21). Engrosamiento que puede ser redondeado o bien plano determinando un perfil con ala (Fig. 6; No 7-I2). 
Variante II.2 - Alcadafe con labio redondeado y leve engrosamiento externo (Fig. 6; $\mathrm{N}^{\circ}$ 13 - 16). Formas semejantes se han localizado en el yacimiento de Pechina (CASTILLO Y MARTínEZ, 1993, pág. II2, lám. XX-2-3) y Huelva (FERNÁNDEZ, 1989, pág. 210, fig. 3-16).

Como hemos visto, este tipo de alcadafe esta más difundido por Andalucía, siendo incorporado como un alcadafe común durante la época emiral para el S.E. de la al-Andalus (ACIÉN et alii, En prensa, 8/3,814), por el contrario está ausente de los tipos emirales levantinos, que desarrollan otro tipo de recipiente, anteriormente comentado.

\section{B.2. CERRADOS:}

Este grupo de recipientes está formado por dos tipos de vasijas:

\section{B.2.I - Cocina:}

OLLA/MARMITA. Están modeladas con pastas rojas y marrones principalmente, existiendo algún caso en el que fueron torneadas con arcillas amarillas. Su desgrasante es mediano, principalmente mineral, cuarzos y micas. Su cuerpo es principalmente globular, incorporando dos asas de puente con sección lenticular, que arrancan de la parte superior del cuerpo y alcanzan el borde del recipiente (Fig. 8; $\mathrm{N}^{\circ}$ 14). Sus bases son planas o ligeramente convexas (Fig. 7; $N^{\circ} \mid-4$ ), existiendo abundantes casos, que como las elaboradas a tornetamano, llevan acopladas tres patas, convirtiéndolas en ollas trípodes (Fig. 7; N 5 y 6).

Las formas de sus bordes definen varios tipos de Ollas:

Tipo I - Ollas con labio Triangular, presenta una terminación diversa, teniendo leve engrosamiento interno, extremo plano o extremo apuntado (Fig. 8; $\mathrm{N}^{\circ} \mid \mathrm{I}-\mathrm{I}$ I). Tipos similares se han documentado en numerosos asentamientos del Sureste peninsular (GUTIÉRREZ, 1988, pág. 72-G2; pág. 101-CM20, CM22, CM23, CM26, CM27) (ACIEN y MARTíNEZ, 1989, pág. 132, fig. 5-2,3) (GÓMEZ, 1992, nº 83) (MOTOS, 1991, fig. 4-38). Estando finalmente incorporada como un tipo emiral en la clasificación tipológica del S.E. de al-Andalus (ACIÉN et alii, En prensa, 4I3).

Tipo II - Ollas con labio Plano, constituye un tipo muy abundante, y como el anterior tiene paralelos en numerosos lugares de alAndalus (CASTILLO Y MARTíNEZ, 1993, pág. 81, lám. II-4) (MOTOS, 199I, fig. 4-7,39,4I) (GUTIÉRREZ, 1988, CMI9). Este tipo puede mostrar diversa inclinación o exvasamiento del borde (Fig. 8; No 12 y I3).

Tipo III - Ollas con labio Bífido (Fig. 8; No 14), muy similares a las localizadas en Bayyana (CASTILLO Y MARTíNEZ, 1993, pág. 81, lám. III)(MOTOS, 1986, pág. 40I, fig. 3-2,3,4). Olla que también es clasificada como propia del período califal en la zona del S.E. de al-Andalus (ACIÉN et alii, En prensa, p. 4/4).

Tipo IV - Ollas con cuello cilíndrico, tan sólo se han localizado tres fragmentos, poseen un cuello muy vertical y una terminación que puede ser apuntada o plana (Fig. 8; $\mathrm{N}^{\circ}$ 15, 16 y 17). Tipos con cierta similitud se han documentado en el Castillón (Granada) (MOTOS, 1991, fig. 7).

Tipo V - Ollas con labio Redondeado, como el tipo II, es bastante numeroso, se caracteriza por poseer un labio sin engrosamiento y de perfil redondeado, aunque con diversa inclinación (Fig. 9; № I-5). Está representado en gran numero de asentamientos de al-Andalus (MALPICA, 1993, pág. 102, lám. XIII-5; pág. 214 , fig. 2-।,2,3,4,5) (ACIÉN Y MARTíNEZ, 1989, pág. I32, fig. 5-4).

\section{B.2.2. Mesa:}

- JARRO/JARRITO - Se realizan en pastas claras muy decantadas, existiendo algunos ejemplos de recipientes modelados en pastas rojas o marrones con desgrasantes finos 0 medianos. Suelen ser de base plana o levemente convexa, cuerpo globular y cuello troncocónico invertido o cilíndrico. Llevan un asa puente de sección redondeada o lenticular de grandes dimensiones, que arranca de la parte superior del cuello o del propio borde, para terminar, unas veces en el cuerpo del recipiente y otras en la base (Fig. $10 / 1 / /$ |2). 
Suelen estar decorados con motivos esquemáticos, principalmente líneas horizontales con tonalidades rojas o marrones, o bien líneas verticales en similares tonalidades, aunque incorporan el negro (Fig. 10; $\mathrm{N}^{\circ}$ I, 8 y 9). Incluso se puede recubrir la superficie externa del recipiente con un engobe negro y decorar la pieza con líneas verticales en blanco (Fig. 10; $N^{\circ} 3$ / Fig. 12; No 5) u otro tipo de motivos geométricos, animales o vegetales (Fig. 12; No 7 y 8). Decoraciones parecidas se han localizado en Córdoba (SERRANO Y CASTILLO, 1992).

Por la forma de su borde podemos distinguir varios tipos de Jarros / Jarritos:

Tipo I - Jarros/Jarritos con labio triangular (Fig. 9; $\mathrm{N}^{0} 6-9$ ), son muy numerosos, pueden tener labio trilobulado, y presentar su extremo superior plano o apuntado, que en algunos casos puede estar pintado con tonalidades rojas o marrones. Tiene paralelos en la mayor parte de los yacimientos estudiados del Sur-este de al-Andalus (MALPICA, 1993, pág.88, lám. VI-15,16; pág. 90, lám. VII-6; pág, 22I, fig. 7-1), el Maraute (GÓMEZ, 1992, n I0I), y aparecen clasificadas en la tipología general de S.E. de alAndalus (ACIÉN et alii, En prensa, 91।).

Tipo II - Jarros/Jarritos de borde redondeado y cuello cóncavo o convexo (Fig. 9; $\mathrm{N}^{\circ}$ 10/I2 / Fig. 10; No I-6), como los anteriores, algunos de ellos tienen el labio trilobulado y poseen una gran asa de puente de sección lenticular o redondeada. Numerosos elementos muestran decoración pintada en la parte superior del borde o en las paredes del recipientes y generalmente en las asas. Tipos similares se han documentado en Granada (MOTOS, 1991, pág. 219, fig. 6-7, pág. 221, fig. 7-2; GÓMEZ, 1992, no 97), Alicante (GUTIÉRREZ, 1988, Z10,Z11,), Murcia (NAVARRO, 1986, pág. 156, n 335, pág. 157, nº 337, pág. 160, n 345), Málaga y Almería (ACIÉN Y MARTÍNEZ, 1989, pág. 132, fig. 5-5,6 ; CASTILLO Y MARTÍNEZ, 1993, pág. 9I, lám. VIII; ACIÉN, 1986, pág. 260, fig. 10-1) y Huelva (FERNÁNDEZ, 1989, pág. 210, fig. 3-4).

Tipo III - Jarros/Jarritos de borde apuntado o redondeado y cuello cilíndrico (Fig. 10; $\mathrm{N}^{\circ}$ 7-10 / Fig. II; No 1-3). Quizá sea uno de los tipos más comunes a todos los asentamientos de al-Andalus. Están realizados con pastas claras muy decantadas, presentan un cuerpo globular o piriforme, cuello cilíndrico y de gran tamaño que se une al labio que puede ser redondeado o apuntado. Poseen una base plana o ligeramente convexa y un asa de grandes proporciones de sección lenticular o redondeada. Generalmente se decoran con líneas verticales de pintura en almagra, que parten de la boca y llegan al cuerpo, y en algunos casos hasta la propia base. Formas con grandes similitudes se han localizado en Alicante (GUTIÉRREZ, 1988, ZI2, ZI3, ZI5, Z16, ZI7, Z18, G6, G7; AZUAR, 1987, pág. 306, plano 13; 1989, pág. 254, fig. 142, encuadradas en períodos posteriores), Granada (MOTOS, 199I, fig. 12-I al 9; GÓMEZ, 1992, nº 103), Huelva (FERNÁNDEZ, 1989, pág. 208, fig. 2-I al 5), Niebla (OLMO, 1986), Málaga y Almería (ACIÉN Y MARTÍNEZ, 1989, pág. 129, fig.3-7,8; CASTILLO Y MARTíNEZ, 1993, pág. 88, lám. VI-6,7,8,1 1,12,13; pág. 90, lám. VII-I,2,4,5; ACIÉN, 1986).

Estos tres primeros tipos de Jarros/Jarritos, están considerados como elementos propios de época emiral en la tipología general del S.E. de al-Andalus (ACIÉN et alii, En prensa, 31।, 314, 315, 316,317 ), aunque principalmente están vidriados.

Tipo IV - Jarros/Jarritos de perfil moldurado triangular (Fig. II; No 4-II), como los dos tipos anteriores son muy numerosos, presentan un perfil diverso, es decir, con el extremo superior redondeado, apuntado, plano, etc. La mayor parte de ellos poseen boca trilobulada, decorada con pintura roja. Están modelados con pastas claras muy decantadas, su cuerpo es globular y su cuello cóncavo. Suelen estar decorados con líneas horizontales de tonalidades rojas y marrones. Un particularismo propio de este tipo de jarro es la molduración realizada en su labio, generalmente una canaladura exterior, pero en algunos casos puede ser interior, o en ambas zonas. Tipos similares han sido documentados en el Castillón (MOTOS, 199।, pág. fig. I0-I al 16 y 36 al 40; fig. II-7।, 74, 76).

Tipo $V$ - Jarros/Jarritos con doble engrosamiento, son poco corrientes, tienen bordes redondeados o planos con doble engrosamiento tanto interno como externo (Fig. 12; $\mathrm{N}^{\circ}$ I-4). 
- JARRA/JARRITA - Constituye un tipo poco abundante y en nuestros asentamientos. Está modelada con pastas claras, amarillas, blancas y naranjas, tienen base plana o levemente convexa, cuerpo globular y cuello cóncavo (Fig. 13; $\mathrm{N}^{\circ}$ I y 2), muy semejantes a los de los jarros y algunos ejemplares con una especie de colador situado en el interior en la zona de unión del cuello con la cuerpo del recipiente (Fig. I3; No 3), formas similares se han localizado en Pechina (CASTILLO Y MARTínEZ, 1993 pág. 109, lám. XVII-9, I0) y Alicante (GUTIÉRREZ, 1988, pág. 93 y 93, Z29). Están decoradas con líneas verticales o bien horizontales en tonos rojos y marrones, principalmente aplicadas en el cuello y cuerpo. Poseen dos asas de puente de sección lenticular o redondeada, también decoradas con líneas horizontales.

Algunos fragmentos de estas series de recipientes cerrados definidos como de mesa, muestran su cara externa e interna cubiertas de una superficie vítrea. Están modelados con pastas claras muy decantadas, los fragmentos están vidriados por sus dos caras en un solo color, bien el verde oscuro o el melado moteado en marrón. Son recipientes de paredes finas, bases planas o levemente convexas, sus cuerpos son globulares de pequeñas dimensiones. Algunos elementos presentan una decoración externa en verde manganeso. Los fragmentos conservados nos muestran dos tipos de recipientes:

Tipo I - Jarra de cuerpo cilíndrico, conservamos dos fragmentos, uno perteneciente a el labio de un jarro vidriado en verde, poseería un tamaño mediano, tendría cuerpo cilíndrico y cuello cóncavo. Y otro de una base ligeramente convexa y cuerpo cilíndrico, vidriada en melado, en ambas quedan restos de una decoración incisa en el primero, en la zona de arranque del cuello, y en el segundo en la parte inferior del cuerpo (Fig. 13; $\mathrm{N}^{\circ} 4$, 5 y 6). De este tipo tenemos paralelos en Bayyana (CASTILLO Y MARTíNEZ, 1989, pág. 88, lám. VII; pág. 109, lám. XVIII-2,3), el Castillón (MOTOS, 1993, pág. 231, fig. 12-10,11), Málaga (IÑIGUEZ Y MAYORGA, 1993, pág. 129, lám. 6-8, I1, 12, 14, 15) y Murcia (NAVARRO, 1986, pág. 158, 159). Este tipo de jarra también ha sido clasificado dentro de la tipología general del S.E. de al-Andalus (ACIÉN et alii, En prensa, 3|2, 3|3).

Tipo II - Jarra de cuerpo piriforme, tenemos un sólo fragmento, tiene el cuerpo piriforme con el pie resaltado, se encuentra vidriado en melado (Fig. 13; No 7). Formas similares se han documentado en el Maraute (GÓMEZ, 1992, n 199).

En menor proporción y sólo exclusivamente en el asentamiento de Puente Tablas, se han recogido fragmentos de jarras, que muestran una decoración en verde manganeso en el exterior y vidriada en melado al interior, el motivo decorativo son piñas (Fig. 13; $N^{\circ} 8$ ).

- REDOMA - Está elaborada con pastas claras muy decantadas, sus bases serían planas o ligeramente convexas, su cuerpo globular y sus cuellos rectos. Por la forma de su borde podemos distinguir dos tipos:

Tipo I - Redoma con labio de perfil redondeado, define un recipiente con un cuello delgado, su borde puede ser ligeramente apuntado y redondeado (Fig. I3; No 9-I I). Tipos similares han sido documentados en Málaga (IÑNGUEZ Y MAYORGA, 1993, pág. 127,lám. 5-4), Alicante (GUTIÉRREZ, 1988, Z40).

Tipo II - Redoma con engrosamientos, define un recipiente de cuello recto o ligeramente cóncavo, su labio puede presentar engrosamiento externo, o bien interno y externo (Fig. 13; No 12 - |4). Formas similares se han documentado en Alicante (GUTIÉRREZ, 1988, Z4I), Málaga y Almería (ACIEN Y MARTíNEZ, 1989, pág. 130, fig. 4-3,5), Málaga (IÑIGUEZ Y MAYORGA, 1993, pág. I27, lám. 5-I, 2, 3, 5, 6), Almería (CASTILLO Y MARTínEZ, 1993, pág. 92, lám. IX-1, 2, 5; pág. II, lám. XIX-9), siendo recogido finalmente como un tipo de redoma emiral del S.E. de al-Andalus (ACIÉN et alii, En prensa, 21।, 212).

Tan sólo tenemos un elemento vidriado, es de pequeño tamaño, cuerpo globular, muy curvado desde el inicio de la base hasta el cuello, este último con forma cilíndrica y estrecho. Su superficie externa está vidriada en melado moteado con pequeñas manchas 
marrones, no conserva el borde (Fig. 13; $\mathrm{N}^{\circ}$ 15). Tipos similares se han localizado en Bayyana (CASTILLO Y MARTíNEZ, 1993, pág. III, lám. XIX-4), Murcia (NAVARRO, 1986, pág. I44, n 305) aunque clasificada como Jarra, Marmuyas (NAVARRO, 1991, pág. 52, fig. 4-NOI-2-82, FO3-I-8) y en Granada (RETUERCE Y CANTO, 1987, pág. 96, fig. b).

- BOTE - Se trata de un recipiente localizado en Cerro Miguelico, conserva parte de la base y cuerpo y una tapadera, tiene base plana, con pequeños vástagos que la convierten en trípode, cuerpo cilíndrico. Está decorado exteriormente en verde y manganeso sobre fondo blanco, reproduciendo un motivo decorativo de piñas (Fig. I4; No I).

\section{B.3. Otras Formas:}

Dentro de este grupo localizamos un único tipo de recipiente utilizado para la Contención de fuego:

- CANDIL - La cazoleta se realiza a torno y a esta se le añade después la piquera y el asa. Responden al Tipo IV de G. ROSELLO (1978), definido por presentar cazoleta lenticular 0 bitroncocónica, y surco circular que rodea el diámetro mayor (Fig. I4; No 2 y 3). El elemento que caracteriza esta forma lo constituye el asa de puente de sección circular, de grandes dimensiones, que parte de la parte inferior de la cazoleta, para terminar en el interior del gollete (Fig. I4; $N^{\circ} 2,3$ y 4). Puede tener algún tipo de decoración, principalmente líneas de pintura roja en el labio del recipiente. Elementos similares han sido documentados en Ceuta (FERNÁNDEZ, 1988, fig. 57), Bayyana (CASTILLO, MARTíNEZ Y ACIÉN, 1987, pág. 545, fig.4) (CASTILLO Y MARTínEZ, 1993, pág. 98, lám. XII-I), Córdoba (CÓRDOBA, 1986, n II8; PAVÓN, 196, pág. 124, fig.96-E; FUERTES et alii, 1993, lám. 2), Écija (RODRÍGUEZ Y NúÑ̃EZ, 1987, fig.30-3,31,32 ), Cádiz (ARANDA, 1984, fig. 2h), Murcia (NAVARRO, 1986; p. VIII, fig. 354, 357, 359 , 36I), en el Zambo (Alicante)(GUTIÉRREZ, 1993, pág. 53, fig. 8-4), Zaragoza (SOUTO, 1987, pág. 44, fig.4-8), Asta Regia (Jerez) (ESTEVE, 1945, lám. XVII-I) y alBasra (Marruecos) (BENCO, 1987, pág. 83, fig. 5-I lb). Así mismo se encuentra clasificado como un candil bastante común en el S.E. de al-Andalus en época emiral (ACIÉN et alii, En prensa, 7II).
Los fragmentos conservados nos muestran la gran homogeneidad existente en esta serie, tan sólo se pueden establecer algunas diferencias en dos zonas, con respecto a su borde pueden presentar labio redondeado o con un leve engrosamiento externo o interno (Fig. I4).

Tan sólo se ha localizado dos fragmentos vidriados, uno correspondiente a una piquera recuperado en el asentamiento de Peñaflor, y el otro, identificado como parte de la cazoleta, documentado en Cerro Miguelico, ambos están vidriados por completo en verde oscuro (Fig. I4; No 7).

Elementos con estas características se han localizado en el Castillón Granada (MOTOS, 1993, pág. 231, fig. 12-13,14) y Bayyana (CASTILLO Y MARTínEZ, 1993, pág. 98, lám. XII-1,2) y por tanto se han clasificado en la tipología general elaborada para el S.E de al-Andalus (ACIÉN et alii, En prensa, 711.2, 712), y finalmente en Murcia (NAVARRO, 1986, pág. 166, n 356, pág. 167, pág. 169) .

\section{CONCLUSIONES}

En general, si comparamos esta clasificación con las elaboradas para otras zonas de al-Andalus, podemos observar las enormes similitudes existentes entre los diferentes tipos y variantes. A pesar de ello, se aprecian una serie diferencias atribuidas a diversos factores, entre los que cabría destacar particularismos regionales o locales.

Como hemos ido señalando, son muy abundantes las semejanzas, no obstante cabe incidir en la ausencia de varios recipientes, que hasta el momento no han sido documentados en asentamientos emirales giennenses, nos referimos a tipos como el vaso, la taza, el arcaduz y el anafre.

Junto a ello, se observan algunas particulariedades en nuestro conjunto, dentro del tipo Ataifor, no aparecen elementos elaborados a mano/torneta como los localizados en Alicante, Granada y Málaga. Sin embargo, una característica que destaca, es la escasa presencia del repie en este recipiente, rasgo repre- 
sentativo en elementos de época califal. Los fragmentos documentados en Jaén, que poseen esta particularidad son muy escasos, presentándolo poco desarrollado, y siempre localizados en asentamientos datados entre finales del siglo IX y los inicios del siglo X.

Con respecto al Candil, en Jaén está ausente el denominado candil múltiple, sin embargo el tipo de candil localizado en la Campiña, de cazoleta con un asa de grandes proporciones que se introduce en el interior del gollete, es muy característico entre los elementos cerámicos de la mayor parte de los asentamientos emirales de al-Andalus.

Las Ollas, junto a los Jarros/as, constituye un grupo muy homogéneo, aunque cabe destacar como un rasgo peculiar de nuestra zona la denominada "Olla Trípode", o bien la olla elaborada a mano/torneta, con cuerpo troncocónico invertido y labio reentrante (Tipo $\mathrm{VI}$ ). Por el contrario, es muy escasa la presencia de las ollas realizadas a mano/torneta, de base plana, cuerpo cilíndrico o abobado y labio reentrante, presentes en númerosos asentamientos andalusíes. La difusión que tuvo por toda la Campiña la de Olla Trípode, determinó que el Anafre apenas fuese empleado como recipiente para la cocción de alimentos.

Otro dato significativo en la muestra es la abundancia de jarros/as, jarritos/as y ollas, que superan las cantidades aportadas por otros recipientes cerámicos. En esta línea, destacaríamos el mayor volumen, en el registro de algunos asentamientos, de materiales elaborados a mano/Torneta lo que podría indicar diferencias cronológicas, que se refuerzan con la presencia, en otros lugares, de más cantidad de elementos a torno asociados con recipientes en verde y manganeso. No obstante, la tipología cerámica desarrollada en este estudio se enmarca en un amplio período cronológico que oscila entre los siglos VIII y X.

Estas matizaciones cronológicas son muy evidentes en los registros de los yacimientos de Cerro Miguelico y el Cerro de Peñaflor, asentamientos que han aportado el mayor volumen de materiales cerámicos. Como se indicó en otros estudios (SALVATIERRA et alii, 1992; Salvatierra y CASTILlo, 1993) Peñaflor tiene un inicio anterior a Cerro Miguelico, teniendo en cuenta la mayor cantidad de cerámica a mano y torneta, y sufre un abandono también anterior, posiblemente entorno al primer cuarto del siglo $X$, hecho confirmado por la ausencia de cerámica verde y manganeso, y otros tipos califales, que por el contrario si están presentes en Cerro Miguelico. La escasa presencia de ataifores en Peñaflor, es otro elemento que confirma la mayor antigüedad de este yacimiento, ya que este tipo de vasija parece generalizarse a partir del período califal, siendo considerablemente más escasa con anterioridad, al menos en el Alto Guadalquivir.

TABLA N I: ESTRUCTURA TIPOLOGICA FORMAL DE LA CAMPIÑA DE JAÉN

\begin{tabular}{|c|c|c|c|c|}
\hline \multirow[t]{5}{*}{ TORNETA / MANO } & Abiertas & Cocina & \multicolumn{2}{|l|}{ CAZUELA } \\
\hline & \multirow[t]{3}{*}{ Cerradas } & Cocina & \multicolumn{2}{|l|}{ OLLA } \\
\hline & & Mesa & \multicolumn{2}{|l|}{ JARRO } \\
\hline & & Contención & \multicolumn{2}{|l|}{ TINAJA } \\
\hline & Otros & Cocina & \multicolumn{2}{|c|}{ TAPADERA/DISCO } \\
\hline \multirow[t]{12}{*}{ TORNO } & \multirow[t]{4}{*}{ Abiertas } & Cocina & \multicolumn{2}{|l|}{ CAZUELA } \\
\hline & & \multirow[t]{2}{*}{ Mesa } & \multirow[t]{2}{*}{ ATAIFOR } & Sin Vidriar \\
\hline & & & & Vidriado \\
\hline & & Uso Múltiple & \multicolumn{2}{|l|}{ ALCADAFE } \\
\hline & \multirow[t]{6}{*}{ Cerradas } & Cocina & \multicolumn{2}{|l|}{ OLLA } \\
\hline & & \multirow[t]{5}{*}{ Mesa } & \multirow[t]{2}{*}{ JARRO / JARRA } & Sin Vidriar \\
\hline & & & & Vidriado \\
\hline & & & BOTE & Vidriado \\
\hline & & & \multirow[t]{2}{*}{ REDOMA } & Sin Vidriar \\
\hline & & & & Vidriado \\
\hline & \multirow[t]{2}{*}{ Otros } & \multirow[t]{2}{*}{ Contención } & \multirow[t]{2}{*}{ CANDIL } & Sin Vidriar \\
\hline & & & & Vidriado \\
\hline
\end{tabular}




\section{BIBLIOGRAFÍA}

ACIÉN ALMANSA, M. (1986): "Cerámica a torno lento en Bezmiliana. Cronología, tipos y difusión". En I Congreso de Arqueología Medieval Española. Vol. IV. Zaragoza, pág. 243-267.

ACIÉN ALMANSA, M.; CASTILLO GALDEANO, F. Y MARTÍNEZ MADRID, R. (1990): "Excavación de un barrio artesanal de Bayyana (Pechina - Almería). En Archeologie Islamique. I. París, pág. 147-I68.

ACIÉN ALMANSA, M.; CASTILLO GALDEANO, F.; FERNÁNDEZ GUIRADO, M...; MARTÍNEZ MADRID, R.; PERAL BEJARANO, C. Y VALLEJO TRIANO, A. (En prensa): "Evolución de los tipos cerámicos en el S.E de alAndalus". En V Coloquio Internacional de Cerámica Medieval en el Mediterráneo Occidental. (Rabat, 1991).

ACIÉN ALMANSA, M. Y MARTÍNEZ MADRID, R. (1989): "Cerámica islámica arcaica del Sur-este de alAndalus". En Boletín de Arqueología Medieval. NN 3. Madrid, pág. |53-19|.

ALVAREZ DELGADO, Y. (1989): "Cerámicas del s. IX de Arcávica (Cuenca)". En Boletín de Arqueología Medieval. Nº 3. Madrid, pág. 109-121.

ARANDA LINARES, C. (1984): "Estudio tipológico de los candiles musulmanes de barro del Museo de Cádiz" en Estudios de Historia y de Arqueología Medievales. III y IV. Cádiz, pág. |53-19|.

AZUAR RUIZ, R. ( 1987): "El posible al-monastir de las Dunas de Guardamar del Segura (Alicante)". En Les illes orientals d' al-Andalus. Palma de Mallorca, pág. 265-309.

AZUAR RUIZ, R. (1989): Denia Islámica. Arqueología y poblamiento, Alicante.

AZUAR RUIZ, R. (Cord.)(1989): La rabita califal de las Dunas de Guardamar (Alicante). Cerámica, epigrafia, fauna y malacofauna. Alicante.

BAZZANA, A. (1979): "Cerámiques médievales: les méthodes de la description analytique appliquées aux productions de l'Espagne orientale". En Mélanges de la Casa de Velázquez. XV. Madrid, pág. 135- 185.

BENCO, N.L. (1987): The early medieval pottery industry at al-Basra. Marocco. Oxford.

BERMÚDEZ CANO, J.M. (1992) "Algunas consideraciones sobre un lote cerámico de los siglos VIII al IX". En Antiquitas. 3. pág. 54-59.

CABALLERO ZOREDA, L. (1989): "Cerámicas de época visigoda y post-visigoda de las provincias de Cáceres, Madrid y Segovia". En Boletín de Arqueología Medieval. No 3. Madrid, p. 75- 107.

CAMP CAZORLA, E. (1943): La cerámica medieval española. Madrid.

CASTILLO ARMENTEROS, JC. (1995): Introducción arqueológica a un proceso histórico. El poblamiento emiral en la Campiña de Jaén. Tesis Doctorales de la Universidad de Jaén. Microfichas, en prensa.
CASTILLO GALDEANO F. Y MARTÍNEZ MADRID, R (1993): "Producciones cerámicas en Bayyana". En MALPICA, A. (Ed.),1993, pág. 69-116.

CASTILLO GALDEANO, F.; MARTÍNEZ MADRID, R. Y ACIÉN ALMANSA, M. (1987): "Urbanismo e industria en Bayyana. Pechina (Almería)". En II Congreso de Arqueología Medieval Española. Tom. II. Madrid, pág. 538-548.

CÓRDOBA (1986): Exposición la mezquita de Córdoba: s. VIII - XV (Catálogo). Córdoba, mayo - junio 1986. Córdoba.

CORTES, L.L. (1954): "La alfarería en Pereruela (Zamora)". En Zephirus. V. pág. I4I-163.

CORTES, L.L. (1958): "Alfarería femenina en Moveros (Zamora)". En Zephirus. IX. pág. 95-I09.

ESCRIBA, F. (1990): La cerámica califal de Benatússer. Valencia

ESTEVE GUERRERO, M. (1945): "Excavaciones de Asta Regia (Mesas de Asta, Jerez). Campaña de 1942-43". En Acta Arqueológica Hispánica. Vol. III. Madrid.

FEITO, J.M. (1985): Cerámica tradicional asturiana. Madrid.

FERNÁNDEZ GABALDÓN, S. (1989): "El despoblado hispanomusulmán de el Ladrillero (Aroche, Huelva). Datos para el estudio del substrato indígena onubense en época islámica". En Boletín Arqueología Medieval. № 3. Madrid, pág. 205-220.

FERNÁNDEZ GABALDÓN, S. (1990): "Primeros datos arqueológicos acerca del Aroche hispanomusulmán (Aroche, Huelva). Estudio de los materiales cerámicos recogidos en superficie" . En Huelva Arqueológica. XII. Huelva, pág. 307-377.

FERNÁNDEZ SOTELO, E. (1988): "Ceuta medieval. Aproxi-mación al estudio de las cerámicas (s. X-XV)". En I Cerámica de uso particular. Ceuta.

FUERTES SANTOS, M. C. Y GONZÁLEZ VIRSEDA, M. (1993):"Avance al estudio tipológico de la cerámica medieval del yacimiento de Cercedilla, Córdoba. Materiales emirales". En IV Congreso de Arqueología Medieval Española. Tomo III. Alicante, pág. 77I-778.

FUERTES SANTOS, M.C. Y GONZÁLEZ VIRSEDA, M (1994): "Nuevos materiales cerámicos emirales de Cercedilla (Córdoba): Ensayo Tipológico". En Anales de Arqueología Cordobesa. 5. Córdoba, pág. 277-301.

GALVE IZQUIERDO, P. (1988): "Aproximación al estudio de la cerámica de época emiral en la ciudad de Zaragoza". En Caesaraugusta. 65, pág. 235 - 261.

GÓMEZ BECERRA, A. (1992): El Maraute (Motril). Un asentamiento medieval en la Costa de Granada. Motril.

GÓMEZ BECERRA, A. (1993): "Cerámica a torneta procedente de El Maraute (Motril). Una primera aproximación a la cerámica altomedieval de la costa de granadina". En MALPICA, A. (Ed.), 1993, pág. |75-191. 
GÓMEZ MORENO, M. (195I): "Cerámica en "El arte árabe español hasta los almohades". En Ars Hispaniae. Vol. III. Madrid, pág. 310-323.

GONZÁLEZ MARTÍ, M. (1944): Cerámica del levante español. Siglos medievales. Tom. I. La loza. Barcelona Madrid.

GUTIÉRREZ LLORET, S. (1988): Cerámica común paleoandalusí del sur de Alicante (Siglos VII - X). Alicante.

GUTIÉRREZ LLORET, S. (1993): "La cerámica paleoandalusí del sureste peninsular (Tudmir): producción y distribución (s. VIII - X)". En MALPICA, A. (Ed.), 1993, pág. 39-65.

INIIGUEZ, C. Y MAYORGA, J. (1993): "Un alfar emiral en Málaga". En MALPICA, A. (Ed.),1993, pág. I 17 - 138.

KIRCHNER, H. (1988): "Las técnicas y los conjuntos documentales". En BARCELÓ, M. et alii Arqueología medieval en las afueras del medievalismo. Barcelona, pág. 88-133.

LLUBíA, M. (1973): Cerámica medieval española. Barcelona.

MALPICA CUELLO, A. (Ed.)(1993): La cerámica altomedieval en el Sur de al-Andalus. Granada.

MATESANZ VERA, P. (1987): "La cerámica medieval cristiana en el Norte (s. IX-XIII) nuevos datos para su estudio". En II Congreso de Arqueología Medieval Española. Tom. I. Madrid, pág. 245-26I.

MOLINOS, M.; SERRANO, J.L;; RÍSQUEZ, C. Y MONTILLA, S. (1994): Un problema de fronteras en la periferia de Tartessos: Las Calañas de Marmolejo. Colección Martínez de Mazas, Univer-sidad de Jaén. Jaén.

MOTOS GUIRAO, E (1986): "Cerámica procedente del poblado de "El Castillón" (Montefrio-Granada)". En I Congreso de Arqueología Medieval Española. Tom. IV. Zaragoza, pág. 383-405.

MOTOS GUIRAO, E. (|99|): El poblado medieval de "El Castillón" (Montefrio - Granada). Granada.

MOTOS GUIRAO, E. (1993): "La cerámica altomedieval de El Castillón (Montefrio - Granada)". En MALPICA, A. (Ed.), 1993, pág. 209-237.

NAVARRO LARA, M.R. (1991): "La cerámica de Marmuyas". En Cuadernos de la Alhambra. Vol. 27. Granada, pág. 27-63.

NAVARRO PALAZÓN, J. (1986) La cerámica islámica en Murcia. Vol. I, Catálogo. Murcia.

OLMO ENCISO, L. (1986): "Cerámica común de época hispanomusulmana en Niebla". II Congreso Internacional de Cerámica Medieval en el Mediterráneo Occidental. (Toledo - 1981). Madrid, pág. 135-139.

PAVON MALDONADO, B. (1966): "Memoria de la excavación de Madinat al-Zahra". En Excavaciones Arqueológicas en España. Vol. 50. Madrid.
RETUERCE VELASCO, M. Y CANTO GARCÍA, A. (1987): "Apuntes sobre la cerámica emiral a partir de dos piezas fechadas por monedas". En II Congreso de Arqueología Medieval Española. Tom. III. Madrid, pág. 93-104.

RÍSQUEZ CUENCA, C. (1992): Las cerámicas de cocción reductora en el Alto Guadalquivir durante la época ibérica: Hacia una tipología contextual. Tesis Doctoral de la Universidad de Granada. Microfíchas.

RÍSQUEZ CUENCA, C. (1995): "Matemáticas y ordenadores en Arqueología. Una propuesta metodológica para trabajar con fragmentos cerámicos". Arqueología y Territorio medieval, Vol. 2. Jaén. pp. 189-223

RÍSQUEZ, C:; HORNOS, F.; RUIZ, A. Y MOLINOS, M. (199|): "Aplicación del análisis multivariante: una propuesta de tipología contextualizada". En FERNÁNDEZ, V. Y FERNÁNDEZ, G. (Ed.): Aplicaciones informáticas en Arqueología. Complutum. I. Madrid, pág. 83-98.

RODRÍGUEZ TEMIÑO, I Y NÚÑEZ PARIENTE DE LEÓN, E. (1987): Excavaciones Arqueológicas en Écija, Diciembre de 1984. Sevilla.

ROSELLÓ BORDOY, G. (1978): Ensayo de sistematización de la cerámica árabe en Mallorca. Palma de Mallorca.

ROSELLÓ BORDOY, G. (1983a): "Nuevas formas en la cerámica de época islámica". En Bolletí de la Societat Arqueológica Lulliana. 39. Palma de Mallorca, pág. 337-360.

ROSELLÓ BORDOY, G. (1983b): "Nuevas formas en la cerámica de época islámica". En Trabajos del Museo de Mallorca. №36. Palma de Mallorca.

SALVATIERRA, V. Y AGUIRRE, F.J. (1987a): "El asentamiento hispanomusulmán de "Cerro Miguelico" (Torredelcampo - Jaén)". En II Congreso de Arqueología Medieval Española. Tom. II. Madrid, pág. | 42-| 48.

SALVATIERRA, V. Y AGUIRRE, F.J. (I 987b): "Prospección con sondeo estratigráfico en "Cerro Miguelico" (Torredelcampo-Jaén)". En Anuario Arqueológico de Andalucía.- 1986. Tom. II. Sevilla, pág. 242-246.

SALVATIERRA, V.; AGUIRRE, F.J. Y CASTILLO, J.C. (|99|): "Excavaciones en el Cerro del Castillo de Peñaflor (Jaén)". En Anuario Arqueológico de Andalucía1989. Vol. II. Sevilla, pág. 298-303.

SALVATIERRA, V. Y CASTILLO, J.C. (1992): "El Cerro de Peñaflor un posible asentamiento beréber en la Campiña de Jaén". En Anaquel de Estudios Árabes. III. Madrid, pág. |53-|6|.

SALVATIERRA, V. Y CASTILLO, I.C. (I 993a): "Las cerámicas precalifales de la Cora de Jaén". En MALPICA, A. (Ed.), 1993, pág. 241-258.

SALVATIERRA, V. Y CASTILLO, I.C. (I993b): "II Campaña de excavaciones en el yacimiento medieval del Cerro del Castillo de Peñaflor (Jaén)". En Anuario Arqueológico de Andalucía-1991. Tomo II. Sevilla, pág. $312-318$ 
SALVATIERRA, V. Y CASTILLO, I.C. (1995): "Peñaflor, un établissement rural d'époque émirale dans la Campiña de Jaén". En Archéologie islamique. 5. París, pág. I I-24.

SALVATIERRA, V.; CASTILLO, J.C. Y PÉREZ, M.C. (1992): "Introducción al estudio de los materiales del despoblado del Cerro del Castillo de Peñaflor". En Anuario Arqueológico de Andalucía-1990. Tom. II. Sevilla, pág. 326-329.

\section{RESUMEN}

Los métodos empleados para elaborar una tipología con las cerámicas islámicas han sido muy diversos, aunque en líneas generales la mayor parte de ellos han seguido las propuestas de G. Roselló. En los últimos años están surgiendo nuevas iniciativas, que plantean métodos diferentes a la hora de abordar las clasificaciones.

Nuestra propuesta metodológica propone un sistema de seriación mixto, que parte de una clasificación formal, realizada en función de los aspectos tecnológicos, formales, funcionales, etc., con la cual se establecen las series de recipientes, y una clasificación estadística, que permite definir los tipos, subtipos y variantes que configuran cada una de estas series, a raíz del estudio morfométrico de los bordes y bases de los recipientes. En este estudio tan sólo hacemos referencia a la primera.

PALABRAS CLAVE: Cerámica, emiral, tipología
SERRANO PENAA, J.L. Y CASTILLO ARMENTEROS, J.L. (1992):"Excavación arqueológica de urgencia en el solar de la Plaza Mármol de Bañuelos S/N y Calle San Alvaro No 8 de Córdoba". En Anuario Arqueológico de Andalucía1990. Tom. III. Sevilla, pág. 88-98.

SOUTO, J.A. (1987): "Cerámicas islámicas excavadas en el Seo del Salvador (Zaragoza), 1980-1986". En Boletín de Arqueología Medieval. № I. Madrid, pág. 39-49.

\section{ABSTRACT}

Agreat variety of methods been used to make a typology of Islamic pottery. Most of them follow Roselló's (1983), although new proposals showing different classifications have arisen in the last few years.

Our method is a mixed one and of a two-fold nature. It consists of a formal classification made on technological, formal an functional grounds ande capable of grouping vessels consistently. Second, it is based on a statical classification, in particular, a morphometric analysis of rims and bottoms capable of deining the types, subtypes and variants of these groups. In this paper, only the former is extensively dealt with. 


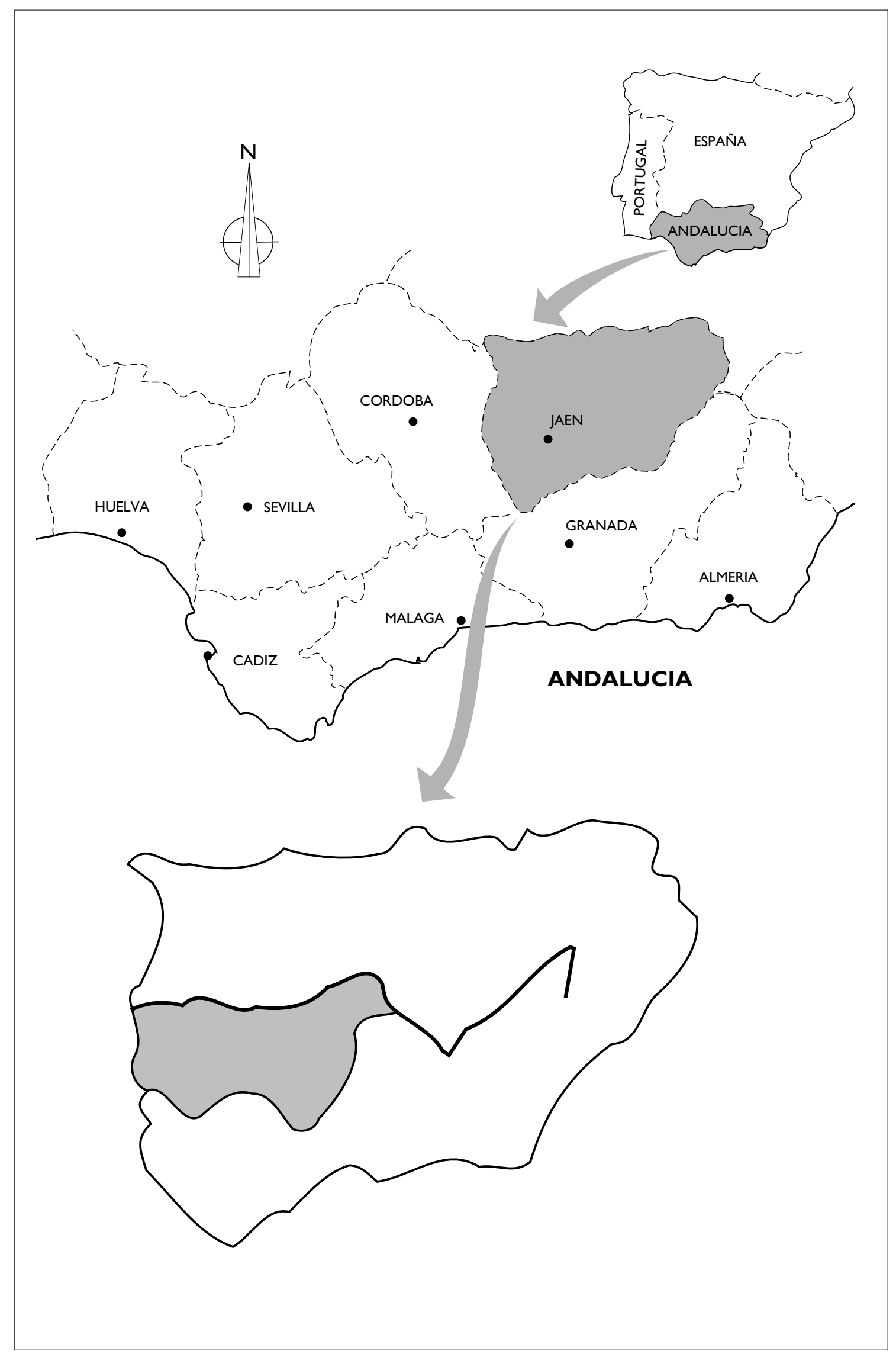

Fig. I. Ubicación de la Campiña giennense 


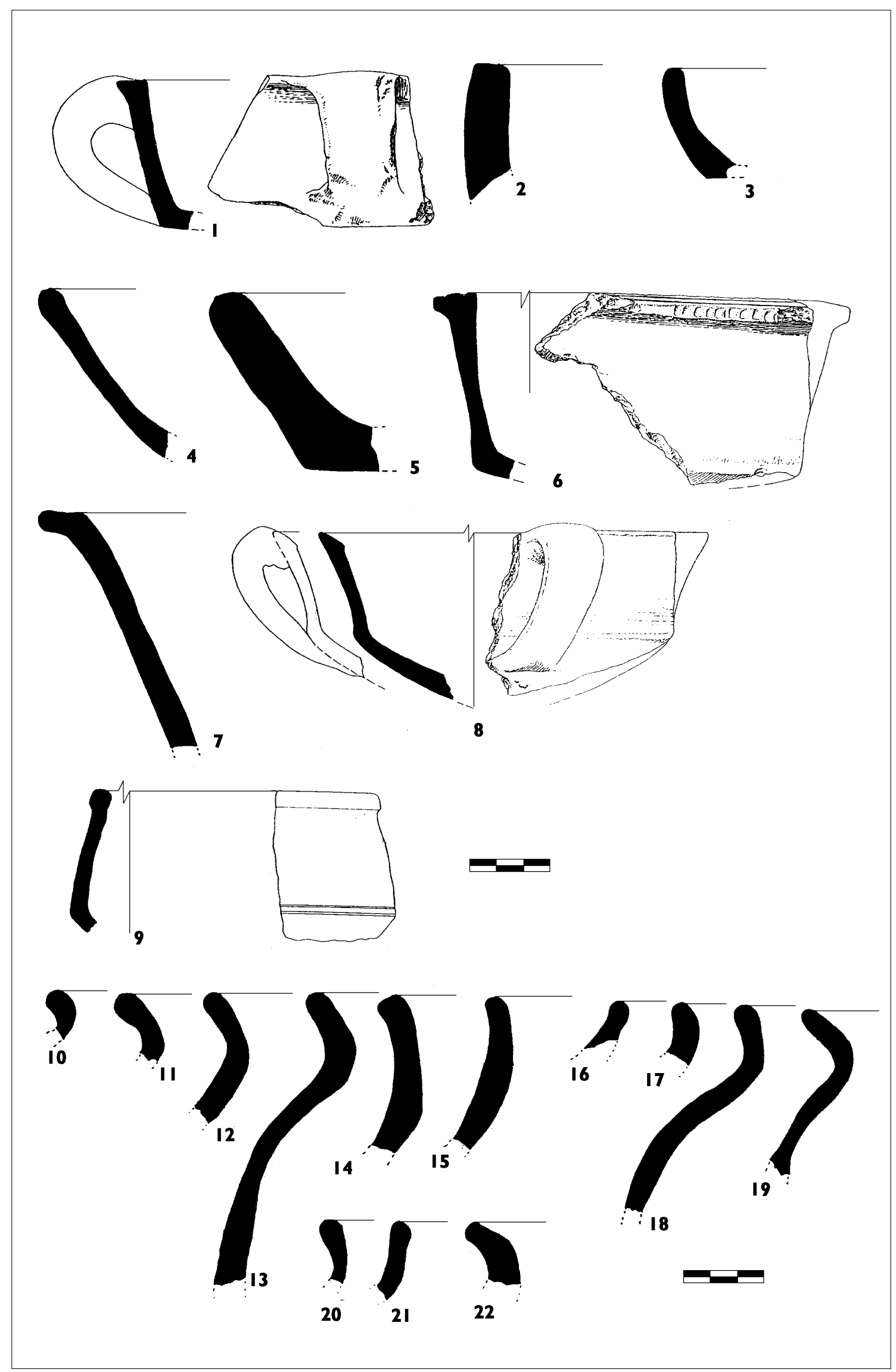

Fig. 2 


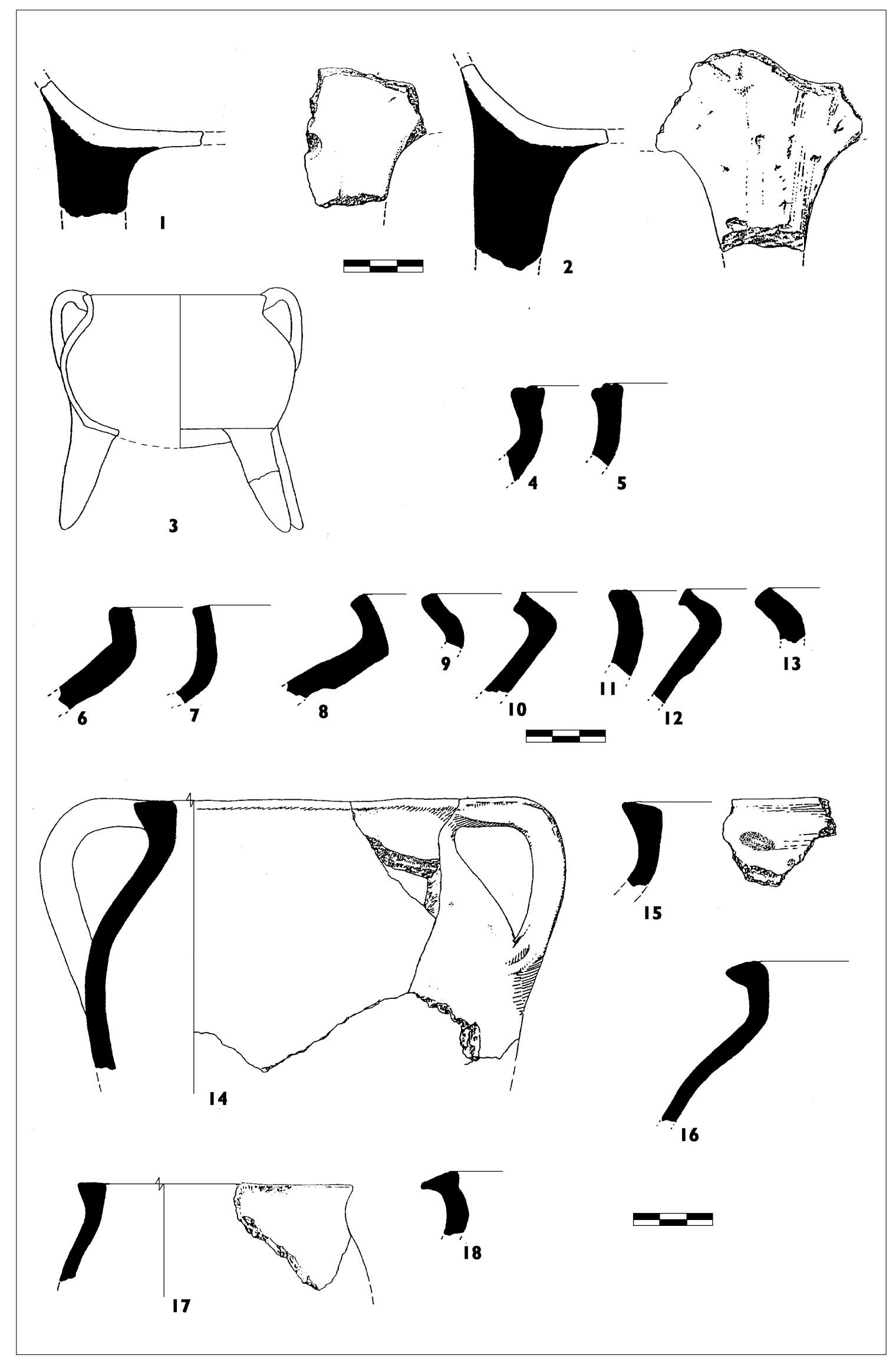

Fig. 3 


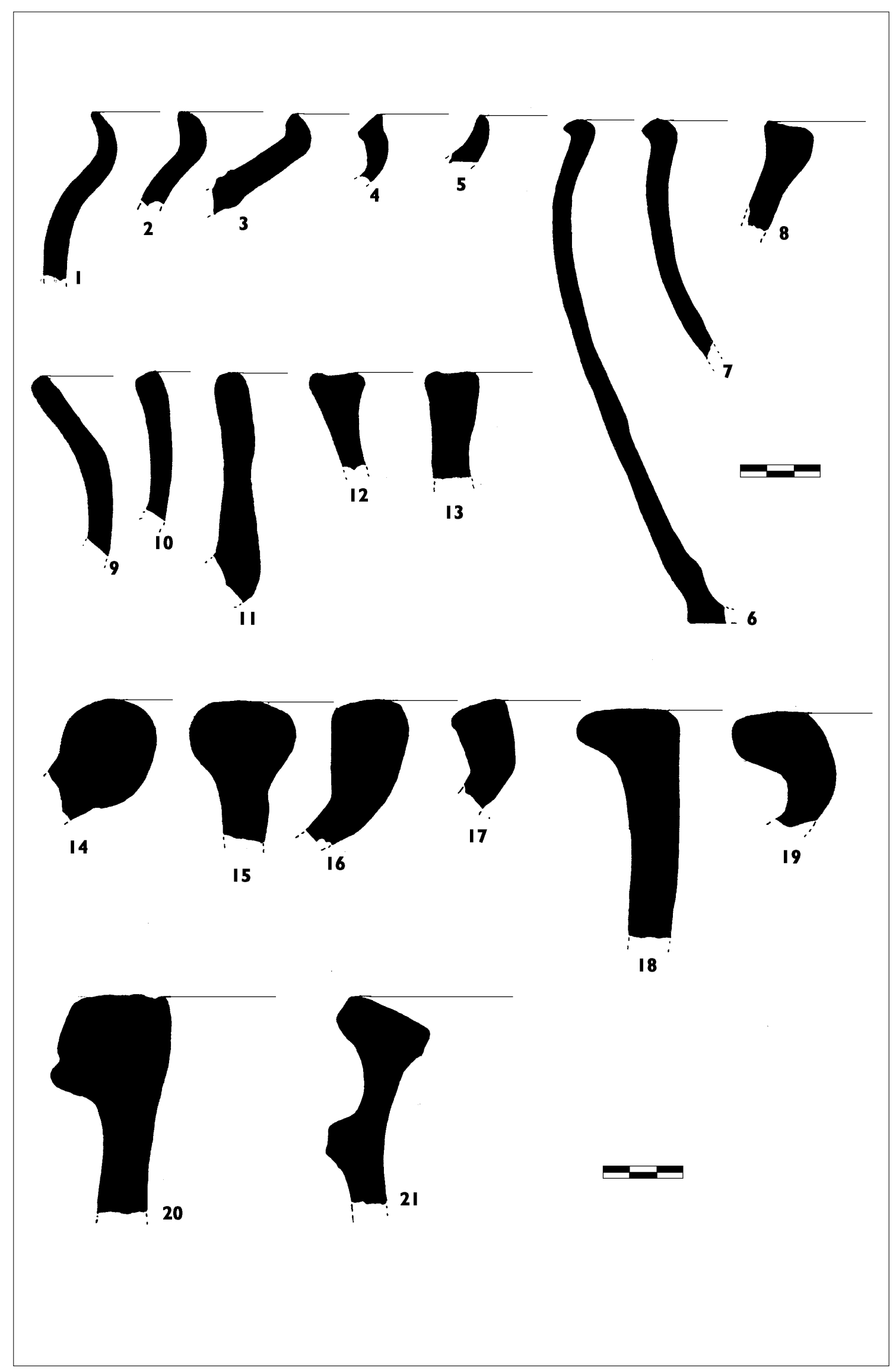

Fig. 4 


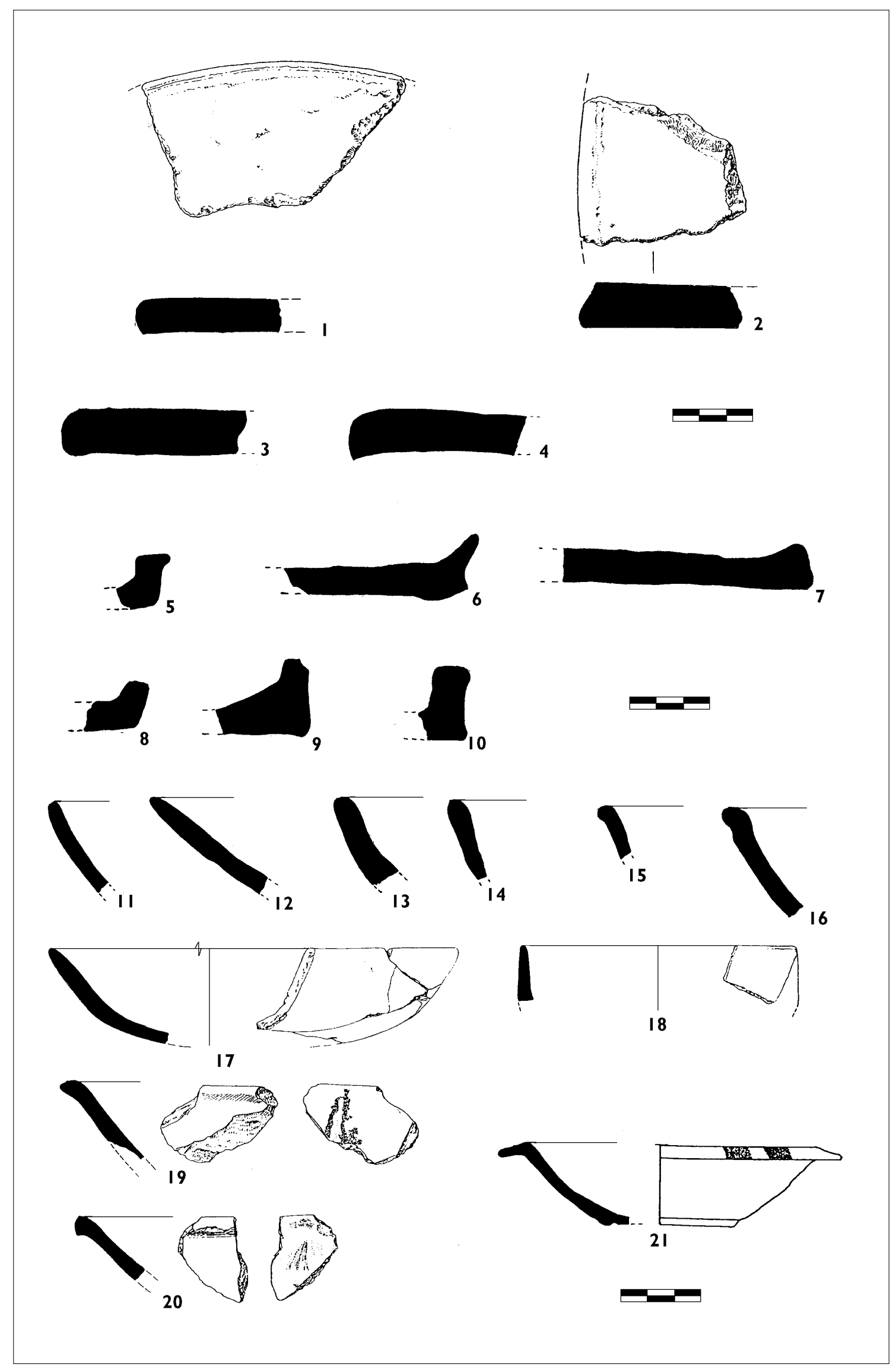

Fig. 5 


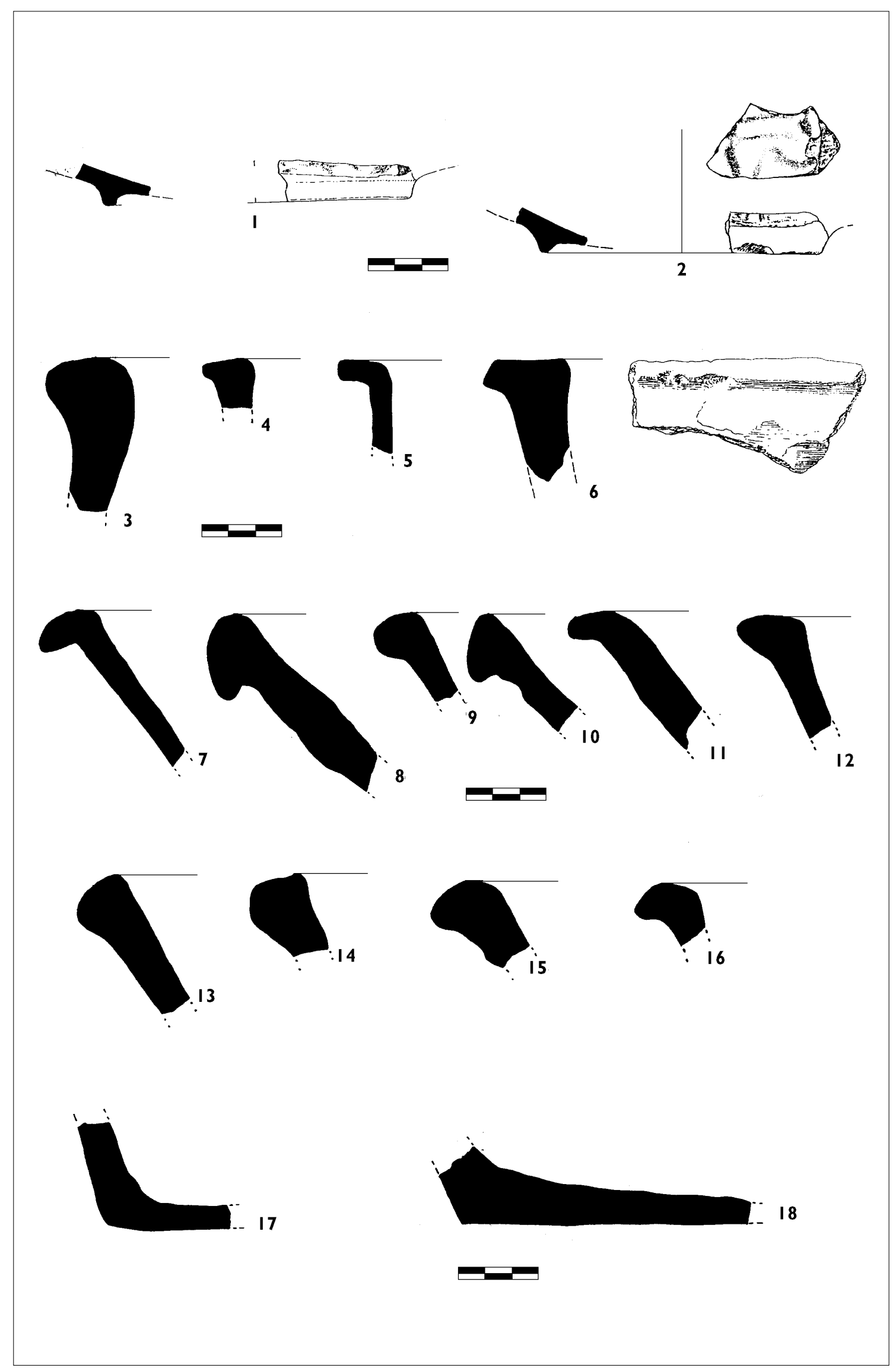

Fig. 6 


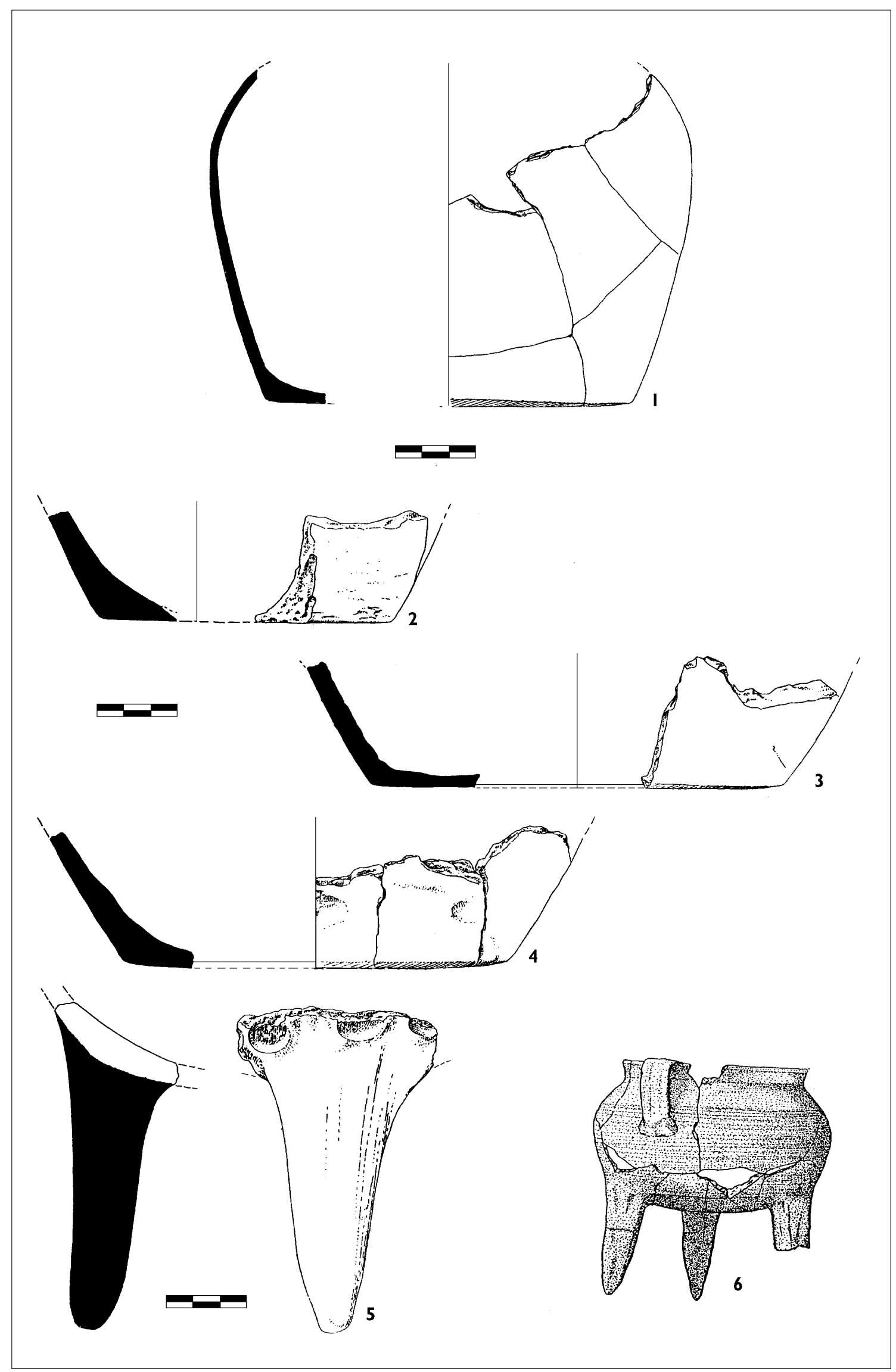

Fig. 7 


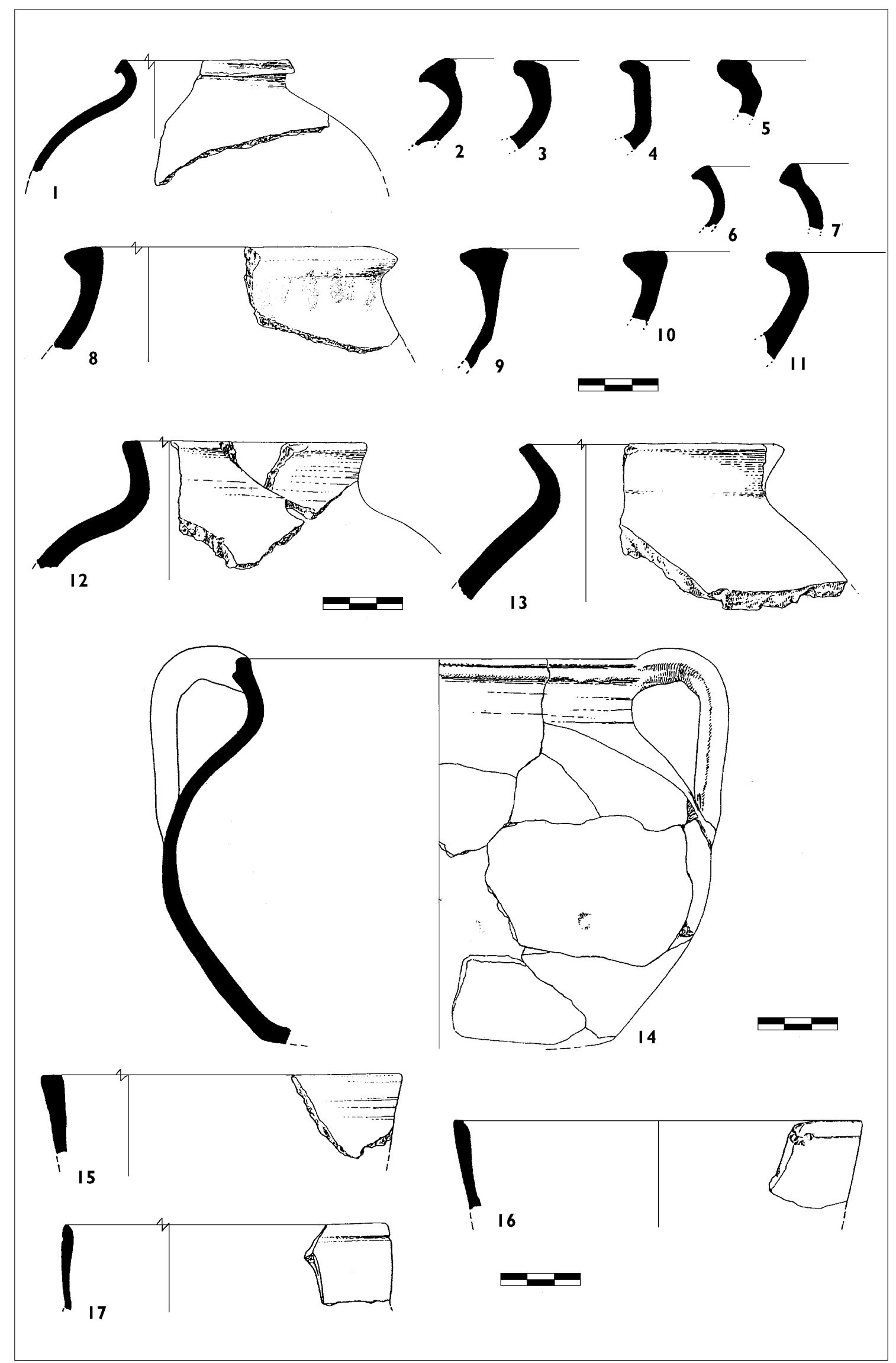

Fig. 8 


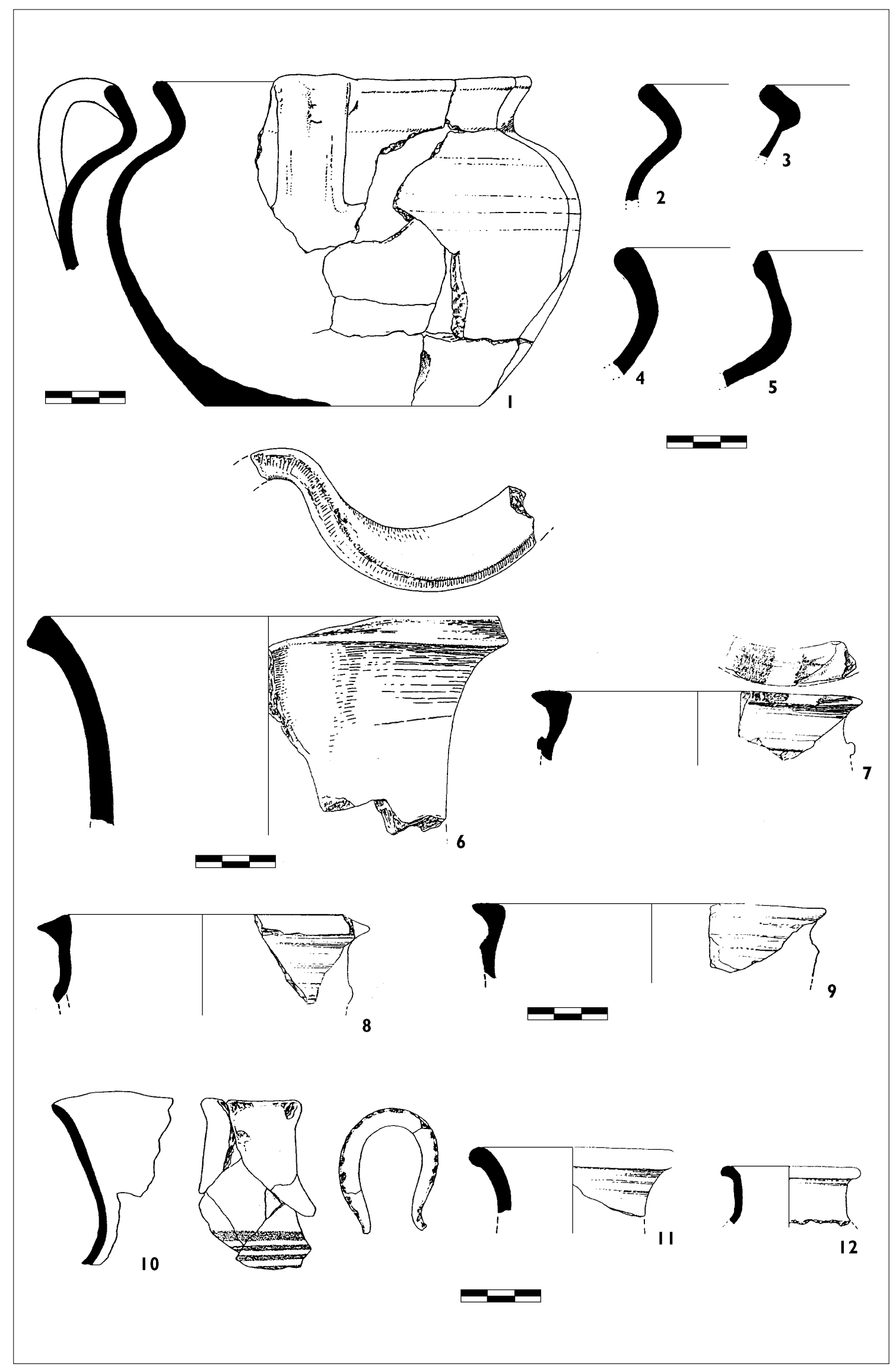

Fig. 9 


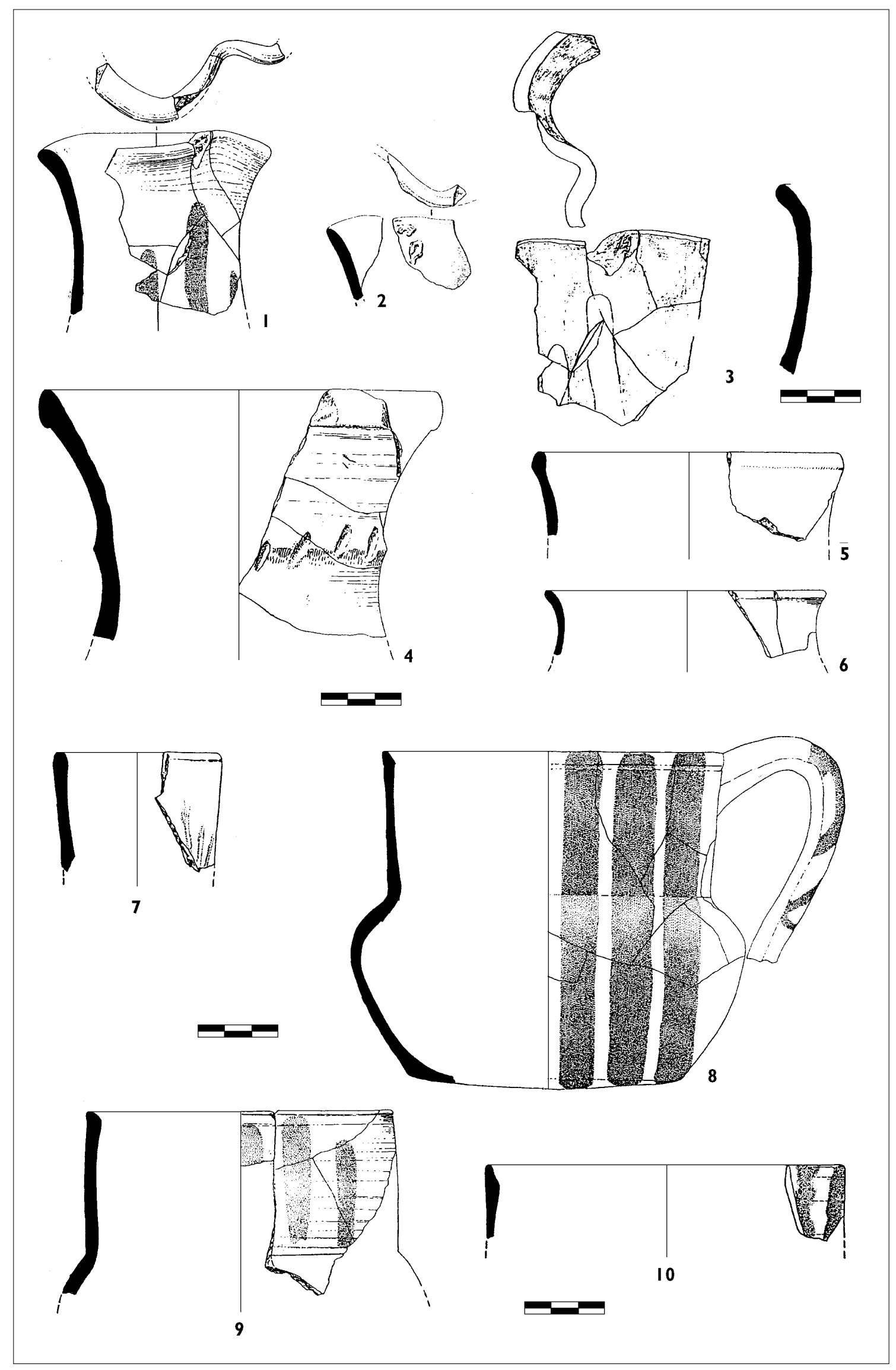

Fig. 10 


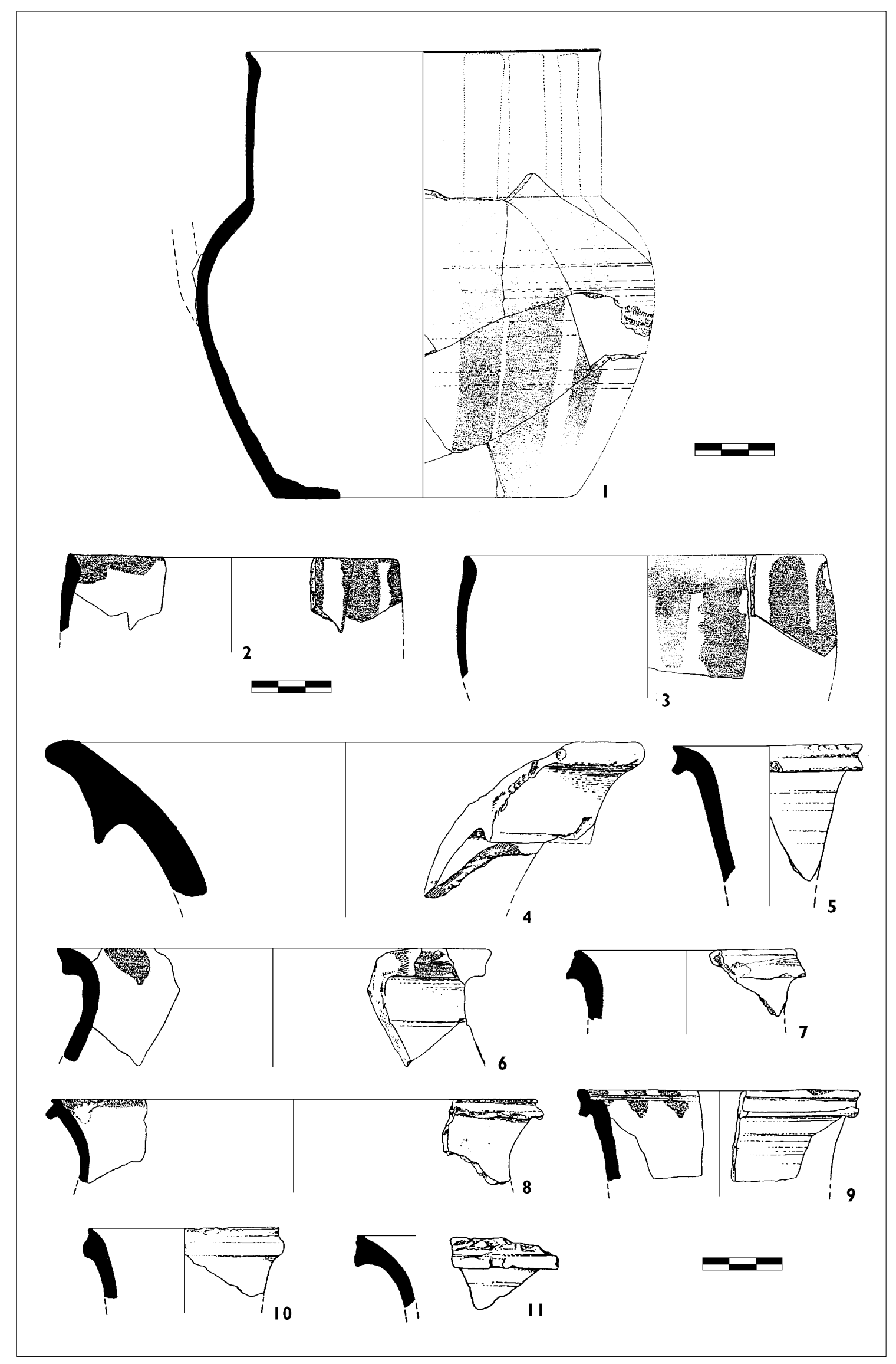

Fig. I I 


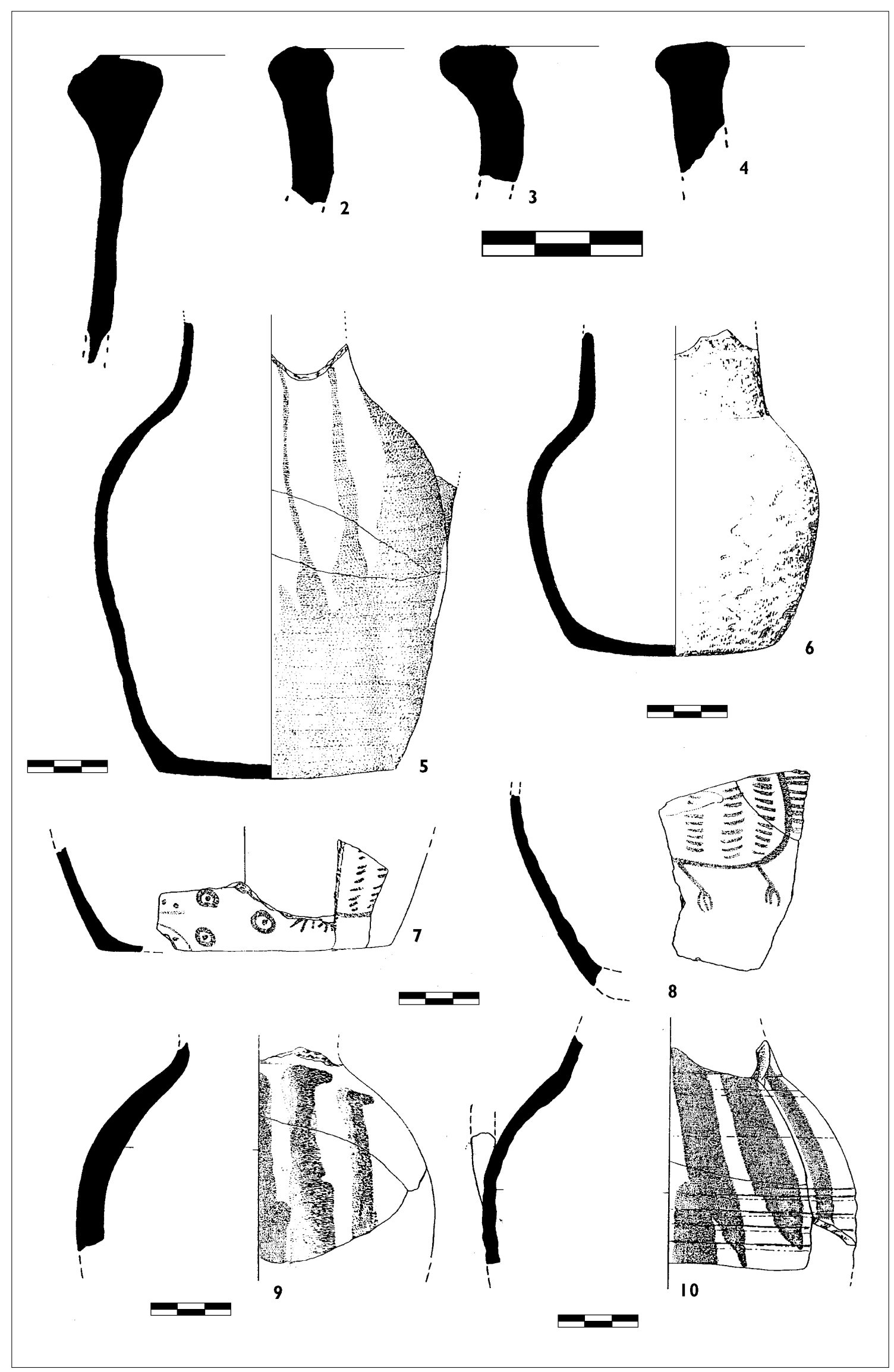

Fig. 12 


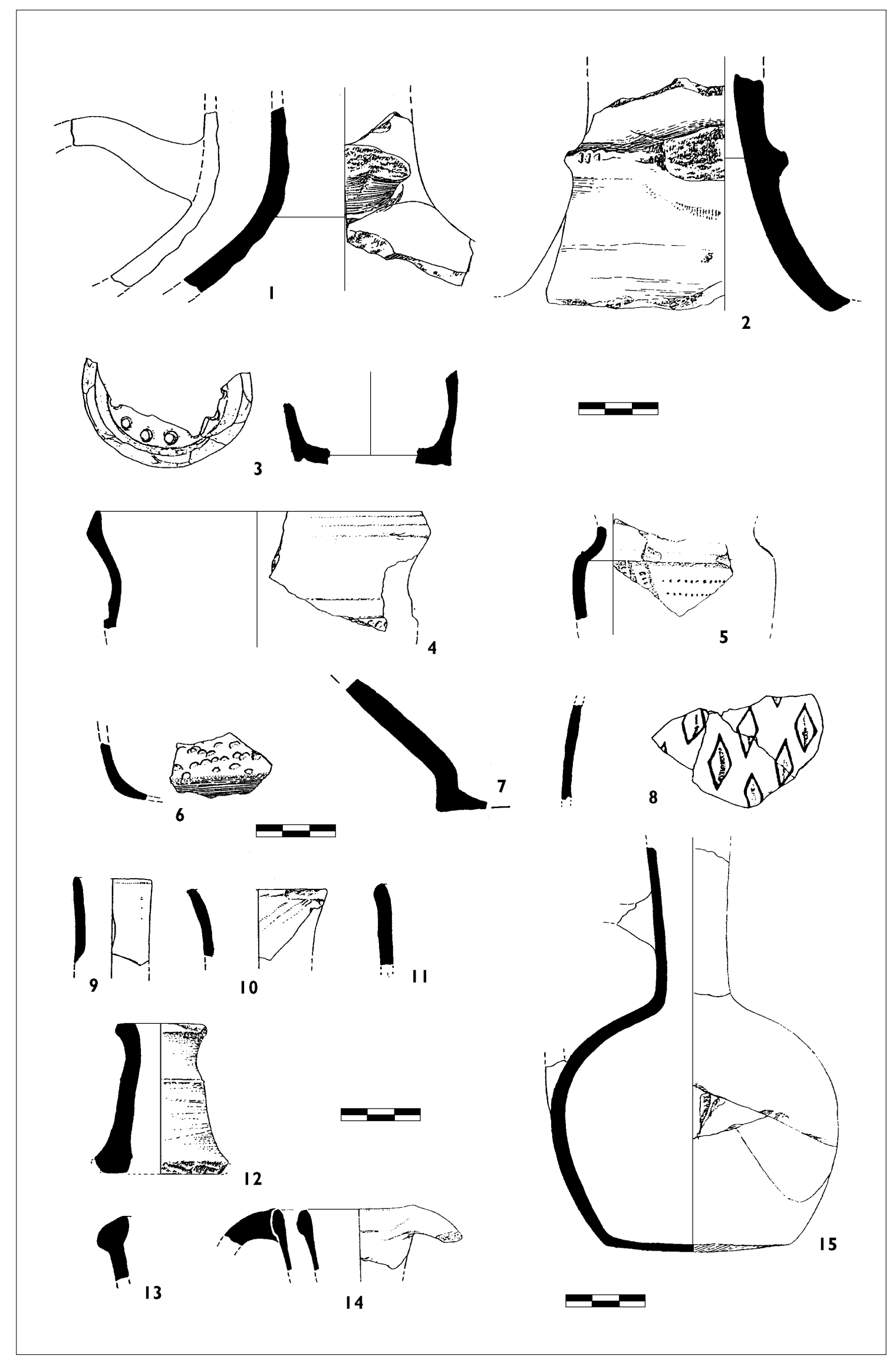

Fig. 13 


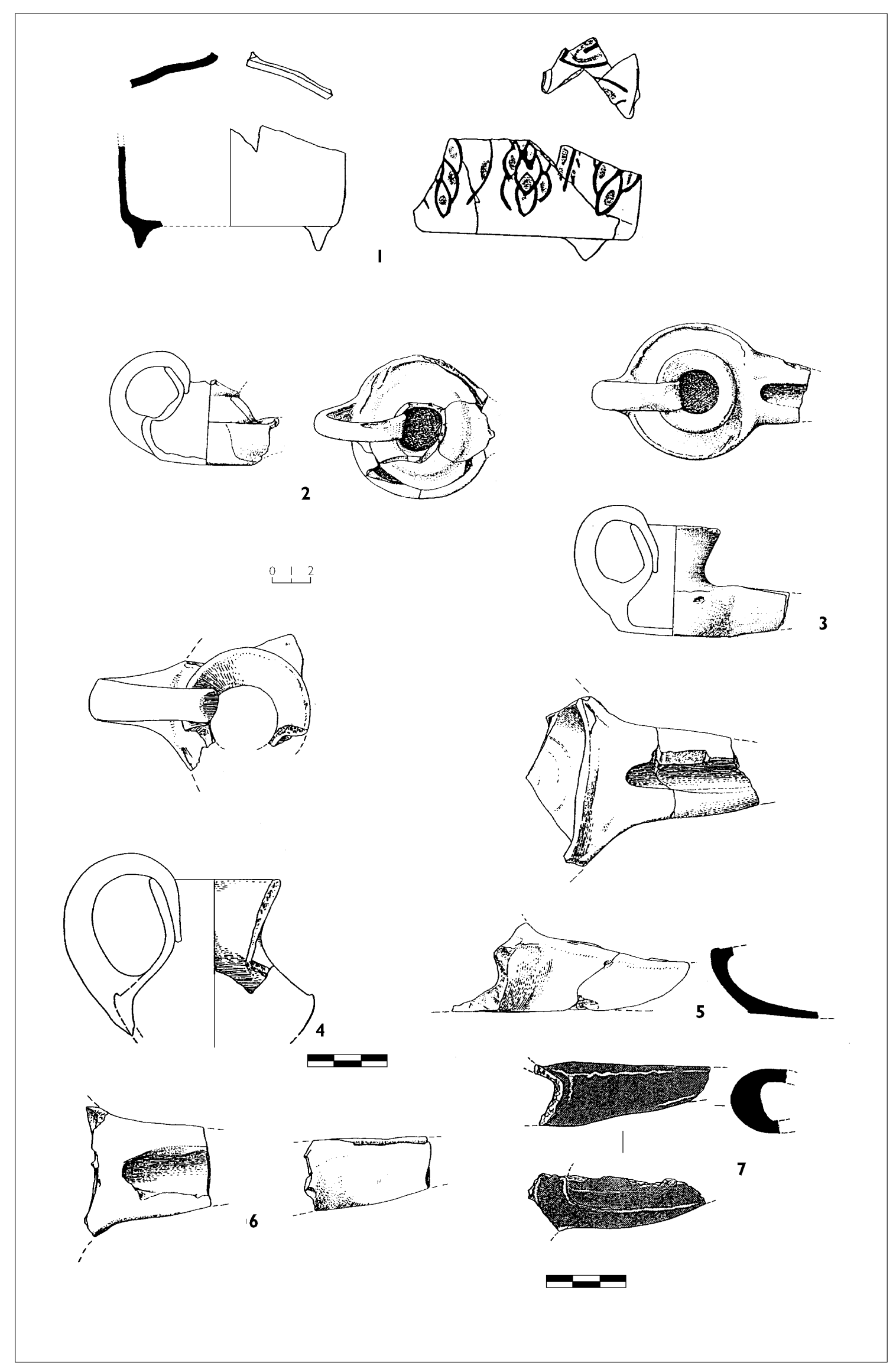

Fig. 14 